\title{
Ionospheric F-region response to the 26 September 2011 geomagnetic storm in the Antarctica American and Australian sectors
}

\author{
Emilia Correia $^{1,2}$, Luca Spogli ${ }^{3,4}$, Lucilla Alfonsi ${ }^{3}$, Claudio Cesaroni ${ }^{3}$, Adriana M. Gulisano ${ }^{5,6,7}$, Evan G. Thomas $^{8}$, \\ Ray F. Hidalgo Ramirez ${ }^{2}$, and Alexandre A. Rodel ${ }^{2}$ \\ ${ }^{1}$ Instituto Nacional de Pesquisas Espaciais, INPE, São José dos Campos, Brazil \\ ${ }^{2}$ Centro de Rádio Astronomia e Astrofísica Mackenzie, Universidade Presbiteriana Mackenzie, \\ 01302-907 São Paulo, Brazil \\ ${ }^{3}$ Istituto Nazionale di Geofisica e Vulcanologia, Rome, Italy \\ ${ }^{4}$ SpacEarth Technology s.r.1., Rome, Italy \\ ${ }^{5}$ Instituto Antártico Argentino/Dirección Nacional del Antártico, Buenos Aires, Argentina \\ ${ }^{6}$ Instituto de Astronomía y Física del Espacio (UBA-CONICET), Buenos Aires, Argentina \\ ${ }^{7}$ Departamento de Física FCEyN Universidad de Buenos Aires, Buenos Aires, Argentina \\ ${ }^{8}$ Thayer School of Engineering, Dartmouth College, Hanover, New Hampshire, USA
}

Correspondence to: Emilia Correia (ecorreia@craam.mackenzie.br)

Received: 19 June 2017 - Revised: 28 August 2017 - Accepted: 2 September 2017 - Published: 5 October 2017

\begin{abstract}
The ionospheric response at middle and high latitudes in the Antarctica American and Australian sectors to the 26-27 September 2011 moderately intense geomagnetic storm was investigated using instruments including an ionosonde, riometer, and GNSS receivers. The multiinstrument observations permitted us to characterize the ionospheric storm-enhanced density (SED) and tongues of ionization (TOIs) as a function of storm time and location, considering the effect of prompt penetration electric fields (PPEFs). During the main phase of the geomagnetic storm, dayside SEDs were observed at middle latitudes, and in the nightside only density depletions were observed from middle to high latitudes. Both the increase and decrease in ionospheric density at middle latitudes can be attributed to a combination of processes, including the PPEF effect just after the storm onset, dominated by disturbance dynamo processes during the evolution of the main phase. Two SEDs-TOIs were identified in the Southern Hemisphere, but only the first episode had a counterpart in the Northern Hemisphere. This difference can be explained by the interhemispheric asymmetry caused by the high-latitude coupling between solar wind and the magnetosphere, which drives the dawn-to-dusk component of the interplanetary magnetic field. The formation of polar TOI is a function of the SED plume location that
\end{abstract}

might be near the dayside cusp from which it can enter the polar cap, which was the case in the Southern Hemisphere. Strong GNSS scintillations were observed at stations collocated with SED plumes at middle latitudes and cusp on the dayside and at polar cap TOIs on the nightside.

Keywords. Ionosphere (Ionospheric disturbances)

\section{Introduction}

The magnetosphere-ionosphere-thermosphere system is strongly disturbed during geomagnetic storms. The ionospheric response to a geomagnetic storm has been studied for decades, but many open questions about its dynamics at regional and global scales still exist (e.g., Prolss, 1995; Buonsanto, 1999; Mendillo, 2006; Danilov, 2013, and references therein). Particularly at high latitudes, ionospheric dynamics are strongly driven by coupling processes involving the solar wind, the interplanetary magnetic field (IMF), and the magnetosphere. During geomagnetic storms, the magnetosphere is compressed, inducing intense electric fields and an increase in magnetospheric convection. The interplanetary electric field (IEF) is mapped along the magnetic field 
lines to the high-latitude ionosphere but can also propagate across the magnetic field lines and appear in the midlatitude and low-latitude ionosphere; in this case it is called a prompt penetration electric field (PPEF). The PPEF effect at the equatorial ionosphere was first identified during substorms (Nishida, 1968), and it was believed that it could last for only $\sim 30 \mathrm{~min}$, which is the magnetospheric shielding time constant (e.g., Tanaka and Hirao, 1973; Senior and Blanc, 1984; Spiro et al., 1988; Fejer et al., 1990). But the effect of PPEF has been observed for hours during the main phase of strong geomagnetic storms, evidencing a long-duration penetration of interplanetary electric field to the low-latitude ionosphere without shielding (Tsurutani et al., 2004, 2008; Huang et al., 2005; Mannucci et al., 2008). High-latitude ionosphere electrodynamics are strongly affected by the mapped IEF that induces various electric fields and also by the polar plasma convection (e.g., Gonzalez et al., 1999). The induced ionospheric electric fields refer to the near-equatorial PPEF (Nishida, 1968), the disturbance dynamo (Blanc and Richmond, 1980), the equatorial polarization (Balan and Bailey, 1995), and the subauroral polarization stream (SAPS; Foster and Burke, 2002). PPEFs are often observed in the equatorial latitudes (e.g., Sastri, 1988), convecting the ionosphere upward in the dayside and downward in the nightside. Particularly during major geomagnetic storms, PPEFs are substantially larger than the fields associated with the normal fountain effect (Tsurutani et al., 2004), lifting the dayside equatorial plasma to higher altitudes and latitudes than normal with the crests of the equatorial ionospheric anomaly (EIA) reaching the middle latitudes. This has been called the dayside ionospheric superfountain (DIS) effect (Tsurutani et al., 2004, 2008). At high latitudes, the precipitation of energetic particles into the thermosphere enhances ionospheric conductivities and generates intense electrical currents (Buonsanto, 1999). The dissipation of these currents by the Joule effect heats the auroral zone, which expands, changing the lower thermospheric composition and driving large-scale neutral winds (Fuller-Rowell et al., 1994; Buonsanto, 1999; Danilov and Lastovicka, 2001). The combination of these ionospheric processes during major geomagnetic storms results in a large-scale thermal plasma redistribution involving the equatorial through the polar latitude regions.

The response of the distinct ionospheric regions to geomagnetic storms is different because the electron density changes are controlled by different physical mechanisms. The lower ionosphere, regions $\mathrm{E}$ and $\mathrm{D}$, shows a significant enhancement of electron density in the auroral zone produced by increased precipitation of energetic particles (Lastovicka, 1996). In contrast, F2-region response to geomagnetic storms shows very complicated spatial and temporal behavior (e.g., Danilov, 2013). They are called ionospheric storms and could present an increase in (positive phase) or a depletion (negative phase) of electron density, which is produced by different mechanisms associated with electrodynamic processes and neutral composition changes (e.g., Danilov and Lastovicka, 2001).

Ionospheric storm morphology is a function of the energy input in the high-latitude upper atmosphere, which is maximized during the main phase of the geomagnetic storms (Gonzalez et al., 1994), and its behavior during the same storm could be very different depending on the station latitude and longitude, local time of storm onset, storm time, and season. The F2-region response to geomagnetic storms is very complex, but a general morphology and physical processes have been established, as described in many review papers (e.g., Prolss, 1995, 2008; Buonsanto, 1999; Mendillo, 2006; Danilov and Lastovicka, 2001; Danilov, 2013).

The negative phase of the ionospheric storms are thought to be well understood: they are mostly observed at high and middle latitudes and occur in all seasons but winter. One of the most significant characteristics is equatorward drift from auroral to middle latitudes, which shows seasonal behavior and is more developed in the summer hemisphere where it penetrates to lower latitudes than in the winter hemisphere (Prolss, 1995, 2008; Buonsanto, 1999). Due to the differences between the background thermospheric and storminduced circulation, the negative phase occurs rather frequently at middle latitudes during winter nighttimes, while in summer it is frequently observed both in the daytime and nighttime (Danilov, 2013). Its physical mechanism was first suggested by Seaton (1956), who attributed the negative phase at high latitudes to changes in the thermosphere produced by the heating of its lower part in the auroral zone. The main source of this heating is the Joule effect, but it could also have some contribution from the direct precipitation of particles (Prolss, 1995). The temperature increase in the F2-region also affects the linear recombination coefficient, which reduces the electron concentration. Thus, the negative phase is formed by composition changes and a temperature increase in the thermosphere (Mikhailov and Foster, 1997; Mansilla, 2008). The equatorward drift of the negative phase occurs preferentially in the post-midnight sector during the main phase of geomagnetic storms (Prolss, 1995). At the equatorial region, the nighttime negative phase observed just after the onset of the main phase storm is due to the dawn-to-dusk electric field associated with the PPEF, which is westward and causes a strong downward drift of ionospheric plasma, increasing the recombination and reducing the electron density.

The morphology of the positive phase is more complicated due to more complex physical processes. It mostly occurs at middle and low latitudes in the winter season. There are various possible mechanisms responsible for the positive phase, namely the F2-region uplifting due to vertical drift, plasma fluxes from the plasmasphere, and downwelling produced by storm-induced thermosphere circulation at low latitudes (e.g., Buonsanto, 1999; Mendillo, 2006; Danilov, 2013). The vertical drift is an important factor that affects the F2-region conditions, and it is controlled by the equatorward 
winds, particularly at middle latitudes where the magnetic field lines are inclined, and by PPEF at equatorial latitudes, which can be strong during major geomagnetic storms. The thermospheric wind circulation favors upward vertical drift during daytime in the winter season at middle latitudes, and at near-equatorial latitudes the upward drift is due to electrodynamic processes due to the EIA anomaly in association with the PPEF effect, which increases the electron concentration because the production is still occurring (e.g., Prolss, 1978; Buonsanto, 1999).

Total electron content (TEC) enhancements observed in the dusk sector at middle latitudes during the main phase of major geomagnetic storms have been shown to be associated with the sunward convection of high-density plasma originating from lower latitudes, which shows a plasma drift toward noon and poleward at ionospheric heights; this is called storm-enhanced density (SED; Foster, 1993). The observations have shown a large-scale redistribution of ionospheric plasma during major geomagnetic storms, covering the equatorial to the polar latitude regions (Foster, 2008). In a first step the PPEF enhances the fountain effect at the equatorial region, increasing the EIA peaks (Tsurutani et al., 2004), which under the effect of the polarization electric field at dusk redistribute the low-latitude TEC in both longitude and latitude, resulting in plumes of SED (Sandel et al., 2001). These SED plumes under the influence of the subauroral polarization stream (SAPS) electric fields are transported into the dayside cusp from which they enter the polar cap, forming the tongue of ionization (TOI; Foster, 2008). The pronounced enhancement of ionospheric density near dusk at middle latitudes observed during the main phase of geomagnetic storms is the called dusk effect (Mendillo et al., 1970; Mendillo, 2006).

The impact of solar wind disturbances on the magnetosphere-ionosphere system results in a highly inhomogeneous ionosphere, producing steep electron density gradients and irregularities. These structures vary on a wide range of scale sizes from centimeters to hundreds of kilometers and affect the performance of radio communication and navigation systems. These density irregularities can produce rapid fluctuations in the amplitude and phase of GNSS (global navigation satellite system) signals. At L-band, amplitude scintillations are due to irregularities with a scale size from hundreds of meters down to tens of meters (according to Fresnel's filtering mechanism), while phase scintillations are caused by structures from a few hundred meters to several kilometers (see, e.g., Kintner et al., 2007). The phase fluctuation is also estimated from rate of TEC (ROT), which gives information about structures with a scale size bigger than the Fresnel scale (on L1 signal about $250 \mathrm{~m}$ ). The occurrence of ionospheric scintillations depends on magnetic local time, season, magnetic activity, solar cycle, and geographic location (Spogli et al., 2009; Li et al., 2010; Alfonsi et al., 2011; Prikryl et al., 2011). The ionospheric regions strongly affected by scintillation are the nightside auroral oval, the cusp on the dayside, and the polar cap at high latitudes, as well the equatorial regions affected by the EIA anomaly. At high and middle latitudes, GPS phase scintillation observations have shown that ionospheric irregularities are primarily enhanced in the cusp in association with storm-enhanced plasma density (SED). A tongue of ionization (TOI) can be formed and broken into patches that are transported into the polar cap (e.g., Aarons et al., 2000; De Franceschi et al., 2008; Spogli et al., 2009, 2013a; Prikryl et al., 2011, 2015a, b, 2016; Thomas et al., 2013; Horvarth and Lovell, 2015). In the auroral oval, GPS scintillation has been observed during energetic particle precipitation events (Skone et al., 2008; Kinrade et al., 2013; Prikryl et al., 2013a, b, 2016).

Most of the work done on specific geomagnetic storms refers to effects in the ionosphere at different sectors in the Northern Hemisphere (e.g., Yizengaw et al., 2005; De Franceschi et al., 2008; Spogli et al., 2009; Prikryl et al., 2011, 2015a, b, 2016; Danilov, 2013; Thomas et al., 2013; Hovart and Lovell, 2015; and references therein) where there is a dense network of instrumentation for ionospheric studies. In contrast, in the Southern Hemisphere where the network of instrumentation is sparse, there is less work and most ionospheric studies have been done in the Australian and African sectors.

The purpose of this paper is to investigate the high-latitude and midlatitude ionospheric response to the 26-27 September 2011 moderately intense geomagnetic storm in the Southern Hemisphere, focusing on the American sector in Antarctica. The ionospheric features associated with this geomagnetic storm were already studied at high latitudes in the Northern Hemisphere by Thomas et al. (2013) and at low and equatorial latitudes by Hairston et al. (2014), so this paper will investigate the features observed at middle and high latitudes in the Southern Hemisphere. The goal is to complete the picture of such a storm by characterizing the dynamics of the disturbed ionosphere and its irregularities during the geomagnetic storm main phase. We use ionosonde, GPS-TEC, and GNSS scintillation measurements taken at the Brazilian station Comandante Ferraz (EACF) on King George Island at middle latitude and at Mario Zucchelli Station (BTN) and Concordia Station (DMC) located in the cusp/cap and polar cap regions, respectively. The results permit us to evaluate the ionospheric dynamics during this storm in Antarctica in comparison with other work and discuss its interhemispheric peculiarities.

The paper proceeds as follows. In Sect. 2 the space weather and geomagnetic conditions are given. In Sect. 3 are the observations and data analysis. The results are in Sect. 4, and the discussion and conclusions are in Sect. 5. 


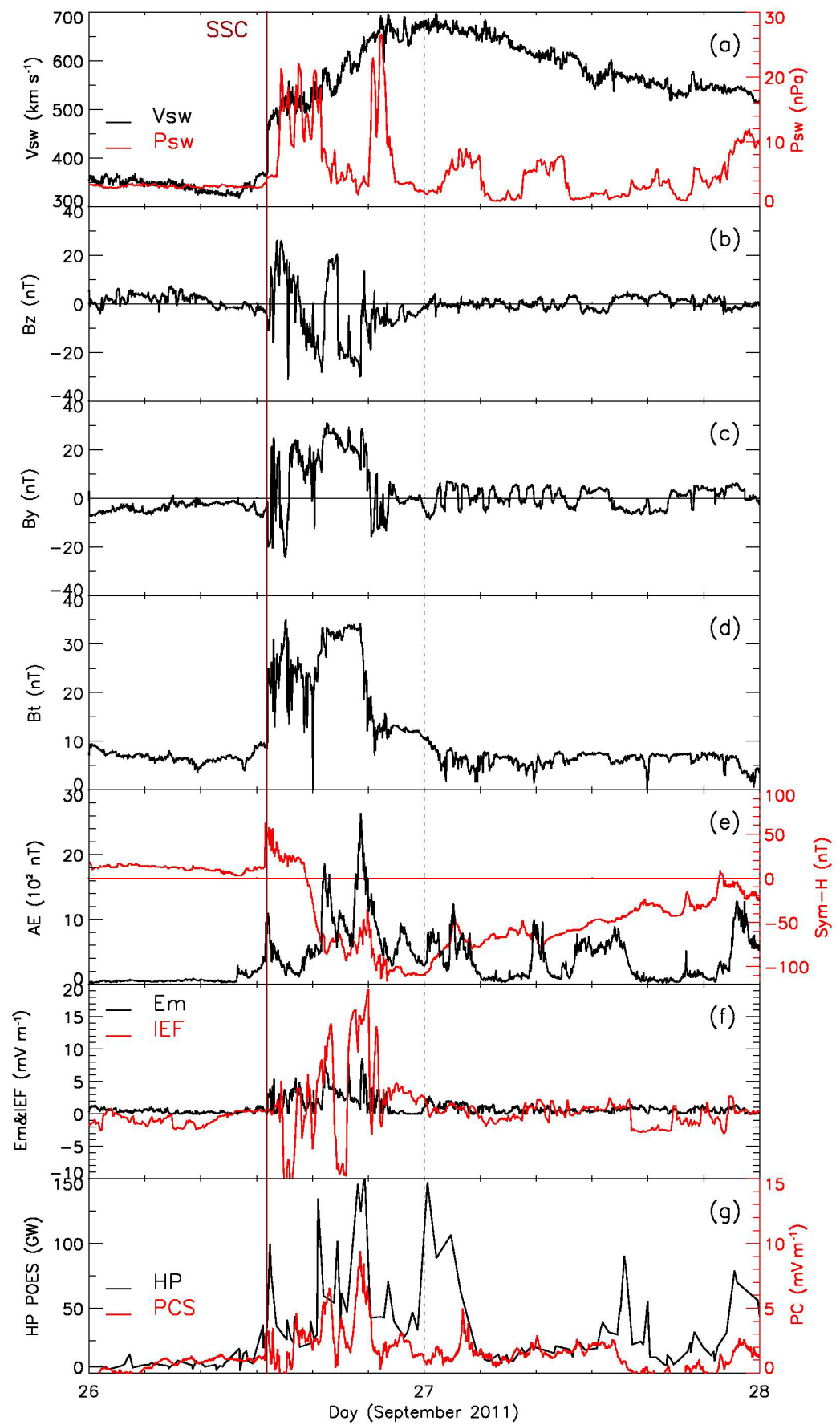

Figure 1. Geomagnetic conditions on 26-27 September 2011. Solar wind (a) velocity (Vsw) and dynamic pressure (Psw), IMF (b) $B_{z}$, (c) $B_{y}$, and (d) Bt components (GSM). The (e) auroral electrojet (AE) and Sym-H, (f) merging electrical field (Em), and interplanetary electric field (IEF). (g) The Southern Hemispheric power (HP POES) index and the polar cap index for the Southern Hemisphere (PCS). The ACE data for IMF components and solar wind parameters were time shifted.

\section{Space weather and geomagnetic conditions}

The magnetosphere-ionosphere system was disturbed on 26 September 2011 by the arrival of an interplanetary shock produced by a coronal mass ejection (CME), which occurred in association with an M7 long-duration X-ray event as observed by the GOES satellite. This disturbance resulted in a moderately strong geomagnetic storm (G2 level) on 2627 September with $\mathrm{Kp}=6$ and Sym-H $\sim-130 \mathrm{nT}$. 
The interplanetary shock arrived on 26 September at $\sim$ 12:40 UT when a sudden change in parameters is observed and leads to a sudden impulse (SI). Sudden variations are observed in the solar wind and interplanetary magnetic field (IMF) parameters (Fig. 1) with increases in the solar wind speed (Vsw) from 350 to $550 \mathrm{~km} \mathrm{~s}^{-1}$, pressure from 5 to $\sim 25 \mathrm{nPa}$, total IMF (Bt) from $\sim 10$ to $30 \mathrm{nT}$, and the beginning of fast fluctuations in the $B_{z}$ and $B_{y}$ components of IMF. The main phase onset of the geomagnetic storm was at $\sim 15: 15$ UT on 26 September when IMF $B_{z}$ turned southward and slowly reached the minimum value of $-30 \mathrm{nT}$ at $\sim$ 17:00 UT, then turned northward. After 18:00 UT, $B_{z}$ turned southward again and remained at $\sim-30 \mathrm{nT}$ until $\sim$ 19:00 UT when it started to oscillate with decreasing amplitude between north and south until the end of the day in association with an increase in the solar wind dynamic pressure that reaches $\sim 25 \mathrm{nPa}$. The IMF $B_{y}$ component is positive from the main phase storm onset until $\sim 20: 00$ UT when it also starts to oscillate with decreasing amplitude until the end of the day, similarly to $B_{z}$. The Sym-H index shows a long initial phase $(\sim 3 \mathrm{~h})$ storm and a complex variation during its main phase reaching two local minima of -70 and $-100 \mathrm{nT}$ at 17:00 and 18:30 UT, respectively. The minimum of the Sym-H index of $\sim-130 \mathrm{nT}$ occurred at 23:00 UT on 26 September.

The auroral activity (AE) and polar cap for the Southern Hemisphere (PCS) indices (Fig. 1e and f) show intensification peaks at $\sim 12: 40,17: 00$, and 19:00 UT in association with SSC and the two Sym-H minima, respectively. The merging electric field (Em; e.g., Kan and Lee, 1979) is used to estimate the energy input into the magnetosphereionosphere system (Fig. 1f). The solar wind motional zonal electric field (IEF; Fig. 1f) is considered to evaluate the PPEF, which occurs during the periods that IMF $B_{z}$ is negative when about $5-12 \%$ of the associated eastward IEF can penetrate into the ionosphere (Gonzalez et al., 1989; Kelley et al., 2003). The IEF is calculated as $-V_{x} \times B_{z}$ (Manucci et al., 2005) with $V_{x}$ being the $x$ component of the solar wind velocity (http://omniweb.gsfc.nasa.gov), which means that the northward positive $B_{z}$ is associated with the occurrence of westward electric fields on the dayside and eastward electric fields on the nightside. The hemispheric power index from NOAA POES (HP POES) for the Southern Hemisphere (Fig. 1g) is used to estimate the power (GW) deposited in the polar region by energetic particle precipitation in the aurora oval. Both these indices also show strong increases in close association with the AE index.

The recovery phase of the geomagnetic storm extended until late on 27 September with IMF Bt at $\sim 5 \mathrm{nT}, B_{z}$ and $B_{y}$ oscillating with $\sim 5 \mathrm{nT}$ of amplitude around zero, and the AE index showing some increases reaching $\sim 1000 \mathrm{nT}$ followed by the PCS index.

The solar wind and interplanetary magnetic field (IMF) data were obtained from the ACE/SWEPAM and OMNIWeb data services (http://www.srl.caltech.edu/
ACE/ASC/level2/lvl2DATA_MAG-SWEPAM.html, http:// omniweb.gsfc.nasa.gov). The IMF components are in geocentric solar magnetospheric (GSM) coordinates. Data from ACE take into account the propagation delays from the spacecraft to the nose of the Earth's bow shock.

The geomagnetic indices used here are the $1 \mathrm{~min}$ auroral electrojet (AE) and Sym-H and the $3 \mathrm{~h} \mathrm{Kp}$, which were obtained from the World Data Center for Geomagnetism, Kyoto (http://wdc.kugi.kyoto-u.ac.jp/wdc/Sec3.html).

The polar cap index for the Southern Hemisphere (PCS) gives a quantitative estimate of geomagnetic activity at polar southern latitudes and also serves as a proxy for energy input into the magnetosphere. Here we use the polar cap index (PCS) that is derived by the magnetic data of Vostok (http://pcindex.org/about-3). NOAA POES hemispheric power (HP POES) for the Southern Hemisphere was obtained from the Space Weather Prediction Center of NOAA (http://legacy-www.swpc.noaa.gov/ftpdir/lists/hpi).

\section{Observations and data analysis}

Figure 2 shows the location of the stations considered in this study. Table 1 summarizes the geographic and geomagnetic coordinates of the stations, including the instrumentation list. The geomagnetic coordinates were computed using the on-line conversion tool available at http://www.ukssdc. ac.uk/cgi-bin/wdec1/coordcnv.pl.

Here we use data from three GNSS ionospheric scintillation and total electron content (TEC) monitor (GISTM) receivers, one operating at the Brazilian Antarctic station Comandante Ferraz (EACF), one at the Italian station Mario Zucchelli (BTN), and one at the Italian-French station Concordia (DMC). The receivers are GISTM GSV 4004B systems (Van Dierendonck et al., 1993), which are Novatel OEM4 dual-frequency systems with special firmware to compute and record the $60 \mathrm{~s}$ amplitude $\left(\mathrm{S} 4^{\prime}\right)$ and phase $\left(\sigma \phi^{\prime}\right)$ scintillation indices of the GPS L1 signal and the $15 \mathrm{~s}$ ionospheric TEC and its changes (rate of TEC, ROT) from the GPS L1 and L2 carrier-phase signals. The system also records the receiver independent exchange format (RINEX) data. The calibrated TEC is obtained from RINEX data using the methodology described by Ciarolo et al. (2007) considering only satellite measurements taken at an elevation angle above $30^{\circ}$.

In order to account for the satellite measurements taken at different elevation angles, TEC and the scintillation indices S4 $4^{\prime}$ and $\sigma \phi^{\prime}$ are projected to the vertical as follows:

$$
\begin{aligned}
& \mathrm{S} 4=\frac{\mathrm{S} 4^{\prime}}{(F(e))^{b}}, \\
& \sigma \phi=\frac{\sigma \phi^{\prime}}{(F(e))^{a}}, \\
& \mathrm{VTEC}=\frac{\text { sTEC }}{F(e)},
\end{aligned}
$$




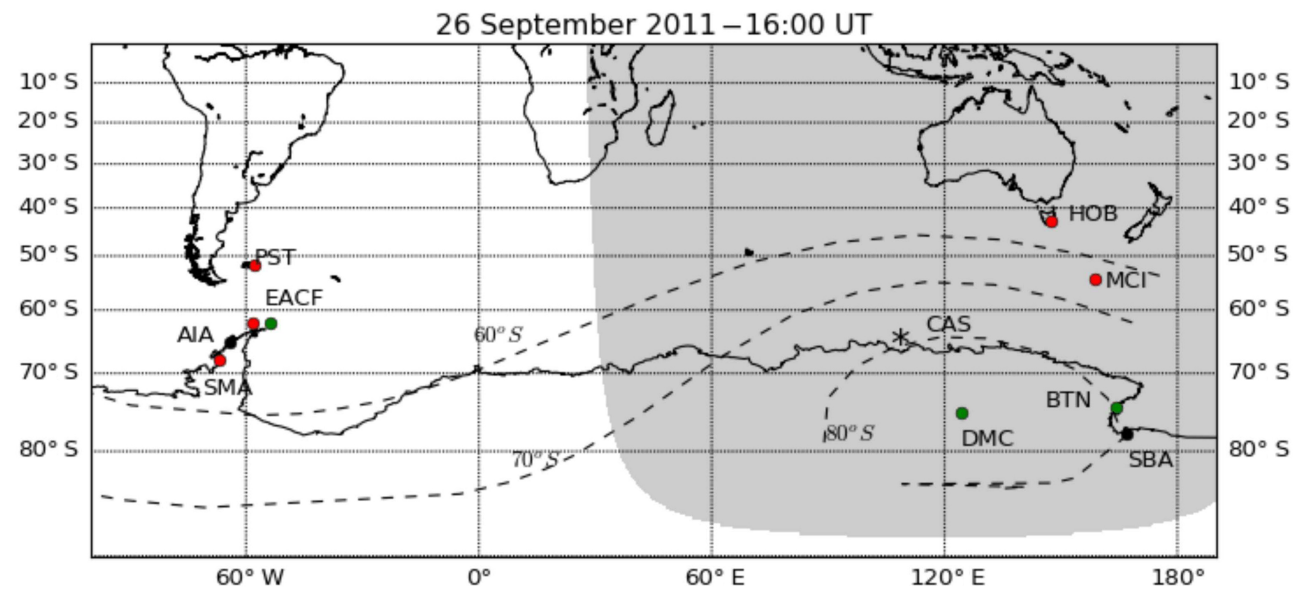

Figure 2. Map showing the station locations and respective instrumentation. The colors and symbols at each station indicate data from ionosondes (red), GNSS receivers (green), magnetometers (black), and riometers ${ }^{*}$ ). The dashed lines indicate isoclinic lines of geomagnetic latitudes. The shaded areas show the night regions at 16:00 UT.

Table 1. Geographic and geomagnetic coordinates of stations with their respective code and instrumentation.

\begin{tabular}{|c|c|c|c|c|c|c|c|}
\hline \multirow[t]{2}{*}{ Station name } & \multicolumn{2}{|c|}{ Geogra. coordinates } & \multicolumn{2}{|c|}{ Geomag. coordinates } & \multirow{2}{*}{$\begin{array}{l}\text { LT } \\
\text { UT }\end{array}$} & \multirow[t]{2}{*}{ MLT mid ${ }^{\mathrm{a}}$} & \multirow[t]{2}{*}{ Instrument list $\mathrm{t}^{\mathrm{b}}$} \\
\hline & Lat $\left({ }^{\circ} \mathrm{N}\right)$ & Long $\left({ }^{\circ} \mathrm{E}\right)$ & Lat $\left({ }^{\circ} \mathrm{N}\right)$ & Long $\left({ }^{\circ} \mathrm{E}\right)$ & & & \\
\hline \multicolumn{8}{|l|}{ American Sector } \\
\hline Port Stanley (PST) & -51.70 & -57.89 & -37.63 & 10.55 & $\mathrm{UT}-4$ & 4 & Iono \\
\hline Comandante Ferraz (EACF) & -62.08 & -58.39 & -47.11 & 11.73 & $\mathrm{UT}-4$ & 4 & GNSS, Iono \\
\hline Akademik Vernadsky (AIA) & -65.25 & -64.25 & -49.89 & 9.12 & $\mathrm{UT}-4$ & 4 & Mag \\
\hline San Martin Base (SMA) & -68.13 & -67.10 & -52.66 & 8.32 & $\mathrm{UT}-4$ & 4 & Iono \\
\hline \multicolumn{8}{|l|}{ Australian Sector } \\
\hline Hobart (HOB) & -42.88 & 147.35 & -54.12 & -133.45 & $\mathrm{UT}+10$ & 13 & Iono \\
\hline Macquarie Island (MCI) & -54.50 & 158.95 & -64.54 & -111.90 & $\mathrm{UT}+10$ & 12 & Iono \\
\hline Casey Station (CAS) & -66.30 & 110.50 & -80.85 & 155.62 & $\mathrm{UT}+8$ & 18 & Riom \\
\hline Mario Zucchelli Station (BTN) & -74.70 & 164.12 & -80.00 & -52.45 & $\mathrm{UT}+12$ & 8 & GNSS \\
\hline Concordia Station (DMC) & -75.25 & 124.17 & -88.68 & 43.26 & $\mathrm{UT}+8$ & 1 & GNSS \\
\hline Scott Base (SBA) & -77.85 & 166.76 & -79.92 & -32.89 & $\mathrm{UT}+12$ & 7 & Mag \\
\hline
\end{tabular}

${ }^{\mathrm{a}}$ Mid is midnight; ${ }^{\mathrm{b}}$ iono is ionosonde, mag is magnetometer, GNSS is GNSS receiver, riom is riometer

where S4, $\sigma \phi$, and VTEC are the vertical values of the respective parameters, sTEC is the slant TEC, $e$ is the satellite elevation angle, and $F(e)$ is the mapping function (Mannucci et al., 1993):

$F(e)=\left[1-\left(\frac{\cos (e)}{1+h / R_{\mathrm{E}}}\right)^{2}\right]^{-1 / 2}$,

where $h$ is the height of the ionospheric piercing point (assumed to be $350 \mathrm{~km}$ ), and $R_{\mathrm{E}}$ is the Earth's radius. The exponents $a$ and $b$ in the expressions of the scintillation indices are assumed to be $a=0.5$ and $b=0.9$ in agreement with Spogli et al. (2009). The sTEC and VTEC are in TEC units $\left(1 \mathrm{TECU}=10^{16} \mathrm{el} \mathrm{m}^{-2}\right)$. A critical discussion about advantages and drawbacks of projecting the scintillation indices to the vertical can be found in Spogli et al. (2013b).
The ionosonde parameters $f o \mathrm{~F} 2$ and $h^{\prime} \mathrm{F} 2$ are obtained from ionograms and refer to the F2-layer vertical incidence critical frequency and the F2-layer bottom virtual height, respectively. At EACF they were obtained from ionograms performed every 5 min with a CADI ionosonde using the software UNIVAP Ionosonde Digital Data Analysis (UDIDA) developed at the University of Paraíba Valley (Fagundes et al., 2005). At San Martin Base, the ionosonde data were obtained from the ionograms performed each hour with an ionospheric sonde (IPS42 Mca; KEL Aerospace). The parameters were obtained from the ionograms interpreted manually one by one by a trained technician at the station making the conversion from the logarithmic scales of the ionogram and using the ordinary rays as usual. These data are complemented by $f o \mathrm{~F} 2$ from ionosondes operating at the Port Stanley (PST), Hobart (HOB), and Macquarie Is- 
land (MCI) stations obtained from the Space Physics Interactive Data Resource (SPIDR; http://spidr.ionosonde.net/ spidr). The analysis considers the $N m \mathrm{~F} 2\left(10^{11} \mathrm{el} \mathrm{m}^{-3}\right)$ calculated from values of $f o \mathrm{~F} 2$ by using the formula $N m \mathrm{~F} 2=$ $1.24 \times\left(f_{o} \mathrm{~F} 2 \text { in } \mathrm{MHz}\right)^{2} \times 10^{10}$.

The ionospheric absorption in the auroral oval was estimated from cosmic noise absorption (CNA) measured at Casey Station, which was obtained from the World Data Centre Space Weather Services (SWS, formally known as IPS Radio and Space Services or IPS; http://www.sws.bom.gov. $\mathrm{au})$.

The surface magnetic field conditions at or near the station locations with GNSS observations are evaluated using the $\mathrm{H}$ (horizontal) component obtained from the INTERMAGNET database (www.intermagnet.org; St-Louis et al., 2012). There are representative data only for the stations Vernadsky (AIA) at middle latitude in the American sector and Scott Base (SBA) in the auroral oval. At high latitudes, the $\mathrm{H}$ component gives the horizontal direction of the auroral electrojet with positive values indicating an electrojet in the eastward direction. Fast decreases in the $\mathrm{H}$ component at high latitudes are associated with changes in the ionospheric currents produced by energetic particle precipitation events into the upper atmosphere.

The energy flux and mean energy of energetic particles precipitating in the southern high latitudes are obtained using the data from the 140 to $150 \mathrm{~nm}$ band (LBHS; e.g., Zhang and Paxton, 2008) from the Special Sensor Ultraviolet Scanning Imager (SSUSI). The sensors are onboard the Defense Meteorological Satellite Program (DMSP) satellites (http://sd-www.jhuapl.edu/Aurora/) and measures the auroral and airglow emissions in the far-ultraviolet bands, providing partial global auroral images (Paxton et al., 2002).

Using the plotting tools developed at Virginia Tech, which are available online at the Space@VT SuperDARN website (http://vt.superdarn.org), it is possible to make side-byside comparisons of the ionospheric convection map using Super Dual Auroral Radar Network (SuperDARN) data with GPS-TEC maps (Thomas et al., 2013) using TEC data from the Madrigal database (http://madrigal.haystack.mit. edu/madrigal/). The line-of-sight (LOS) velocities measured with SuperDARN radars give information about decameterscale plasma irregularities in the ionosphere (Greenwald et al., 1995; Chisham et al., 2007). The global TEC maps are processed using the MIT Automated Processing of GPS (MAPGPS) software package (Rideout and Coster, 2006). These combined maps are used to spatially characterize ionospheric convection and plasma irregularities.

\section{Results}

To characterize the ionospheric response to the geomagnetic storm that occurred on 26-27 September 2011 as a function of storm time, local time, and station geomagnetic location, we use GNSS and ionosonde data from receivers operating at stations located from middle to high latitudes in the Antarctica American and Australian sectors (Fig. 2), which are representative of daytime and nighttime sectors, respectively. The data coverage is not the same in both sectors because in the American sector the instrumentation used for the present study is only over the Antarctic Peninsula at middle-latitude regions, while in the Australian sector there are stations from middle to high latitudes.

The VTEC, $N m \mathrm{~F} 2$, and $h^{\prime} \mathrm{F} 2$ variations are compared with a quiet day curve (QDC) obtained from averaging four nearby geomagnetically quiet days with $\mathrm{Kp}<2$ and $\mathrm{AE}<$ $200 \mathrm{nT}$. The SD $(\sigma)$ of VTEC, $N m \mathrm{~F} 2$, and $h^{\prime} \mathrm{F} 2$ parameters is about $1 \mathrm{TECU}, 0.4 \times 10^{11} \mathrm{elm}^{-3}$, and $25 \mathrm{~km}$, respectively, and they are shown as error bars in the QDC curves (Fig. 3).

\subsection{Ionospheric response in the Antarctica American sector}

The main phase of the geomagnetic storm started at $\sim$ 15:00 UT (11:00 LT) and peaked at $\sim 23: 00$ UT (21:00 LT) on 26 September, which means from noon to night in this sector. The $N m \mathrm{~F} 2$ and VTEC parameters have values always above the quiet day level, showing that the positive phase of the ionospheric storm is dominant during the main phase storm at middle latitudes (Fig. 3a) where it started to develop at the geomagnetic storm onset.

The ionosonde data show three $N m \mathrm{~F} 2$ enhancements. The first one is $\sim 40 \%$ at PST and EACF and $10 \%$ at SMA with a peak at $\sim 16: 00 \mathrm{UT}(\sim 12: 00 \mathrm{LT}$, local noon time $)$ at the beginning of the main phase storm. The second one is $\sim 130 \%$ at PST, $280 \%$ at EACF, and $100 \%$ at SMA with a peak at $\sim 20: 00$ UT (16:00 LT, local afternoon). The third one is $\sim 240 \%$ at PST and $250 \%$ at EACF with no definition at SMA and a peak at $\sim$ 23:00 UT (19:00 LT, dusk). Afterwards it presents an abrupt drop, achieving values below the quiet day level after $\sim$ 24:00 UT (20:00 LT). Each $N m$ F2 enhancement occurred just after a rise of $\sim 40,100$, and $50 \mathrm{~km}$ in the $h^{\prime} \mathrm{F} 2$ parameter as observed at the EACF and SMA stations.

VTEC data from the EACF station also show three enhancements above the quiet day level in close association with the ones observed in $N m \mathrm{~F} 2$. The VTEC enhancements were $\sim 100,300$, and $180 \%$ (Fig. 3a bottom). The comparison between $N m \mathrm{~F} 2$ and VTEC enhancements at EACF shows that the first density increase was much more pronounced in VTEC and the second one was of the same intensity in both parameters, while the third one is more intense in the $N m$ F2. The first enhancement at $\sim$ 17:00 UT shows an increase in VTEC $\sim 2$ times stronger than in $N m \mathrm{~F} 2$, suggesting that the electron concentration changes occurred at altitudes above the F2-layer maximum at which the electrodynamical processes (PPEF) might be dominant (e.g., Tsurutani et al., 2008; Danilov, 2013) during a period of slow intensification of IMF $B_{z}$ in southern direction. The second one at $\sim$ 20:00 UT occurred after a sudden southern turning 


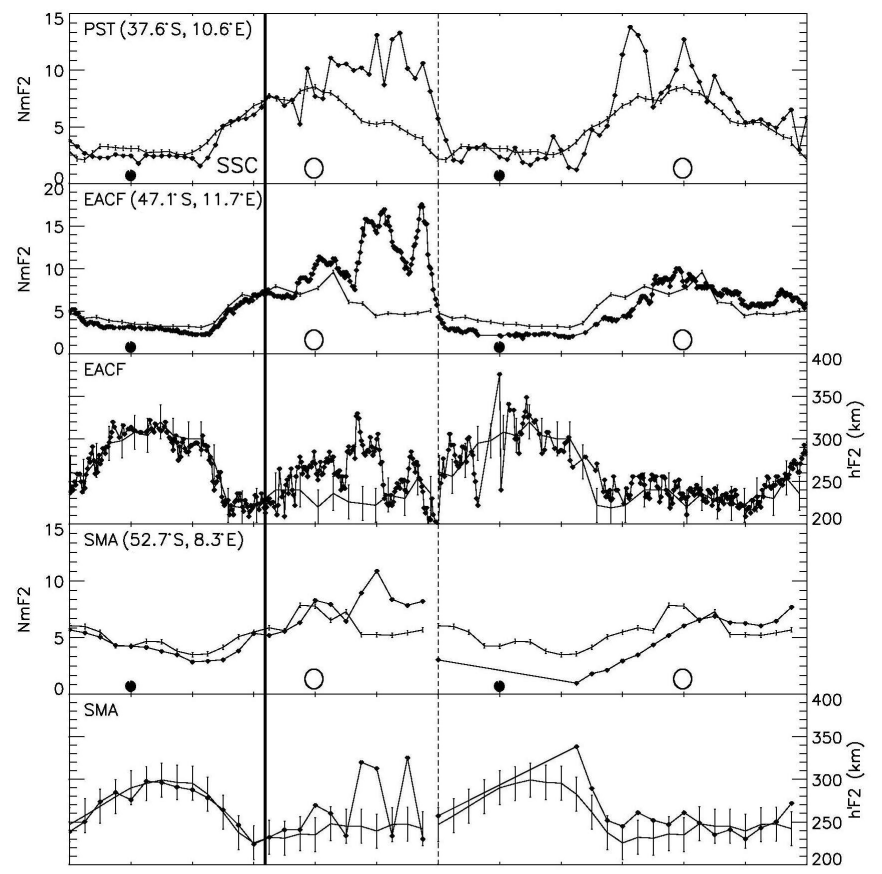

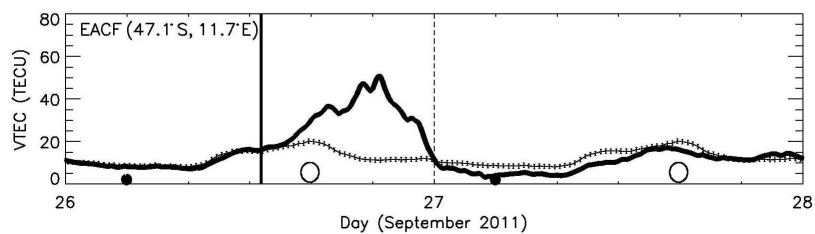

(a)
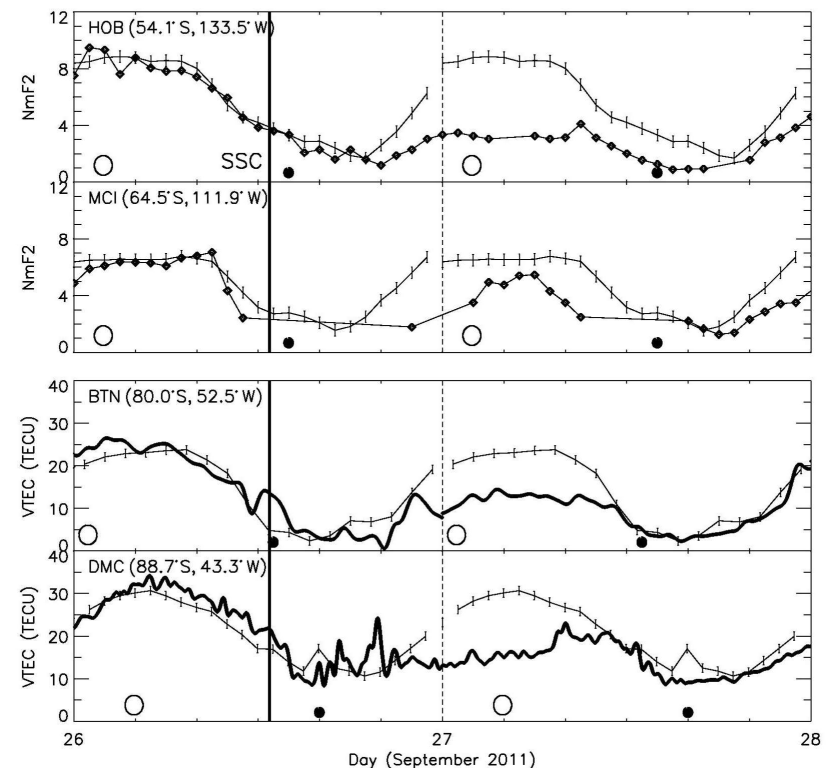

(b)

Figure 3. Variations in $N m \mathrm{~F} 2$ and VTEC measured by instruments in the (a) Antarctica American and (b) Antarctica Australian sectors during the geomagnetic storm that occurred on 26-27 September 2011 (dotted line, darker curves) compared to the quiet day curve (light curves with error bars). Station names and geomagnetic coordinates are shown on the panels. $N m \mathrm{~F} 2$ is in units of $10^{11} \mathrm{el} \mathrm{m}{ }^{-3}$. The error bars on QDC curves refer to the $\mathrm{SD}( \pm \sigma)$ of the respective parameter.

of IMF $B_{z}$ and shows a similar increase in both parameters, suggesting that the density increase was in the height of the layer maximum and might be mostly due to the influence of meridional neutral winds generated by the dynamo disturbance (e.g., Prolss, 1995; Buonsanto, 1999; Mendillo, 2006). The third enhancement occurred at $\sim 23: 00$ UT during the evening hours and can be attributed to the dusk effect in the F-region, which is a combination of mechanisms including neutral winds and neutral composition changes (Buonsanto, 1999).

During the recovery phase that started early on 27 September, the $N m \mathrm{~F} 2$ parameter values are below the QDC at all stations. Between 00:00 and 14:00 UT, $N m F 2$ shows a density depletion of $\sim 30 \%$ at EACF, $\sim 60 \%$ at SMA, and only a small depletion at PST. Afterwards and until the end of the recovery phase late on 27 September, it practically returned to quiet conditions showing no significant departure from QDC. Only at the PST station during the afternoon does $N m \mathrm{~F} 2$ show three strong enhancements superimposed on the slow depletion variation. VTEC parameter at EACF shows variation very similar to $N m \mathrm{~F} 2$.

\subsection{Ionospheric response in the Antarctica Australian sector}

The geomagnetic storm in this sector started near local midnight. $N m \mathrm{~F} 2$ and VTEC parameters predominantly show values below the QDC level during the entire geomagnetic storm (Fig. 3b) at all stations.

During the main phase storm the $\mathrm{NmF} 2$ parameter suggests that the density depletion started earlier in the auroral oval, as seen in the measurements taken at the MCI station. Here the values dropped below the QDC level after $\sim$ 10:00 UT (20:00 LT) on 26 September, even before the time of the SSC, and reached a depletion of $\sim 60 \%$ in the maximum of the main phase at the end of the day (morning hours). At the middle-latitude $\mathrm{HOB}$ station, the $\mathrm{NmF} 2$ values show a small depletion between 15:00 and 20:00 UT (after midnight), which increases afterwards also reaching 


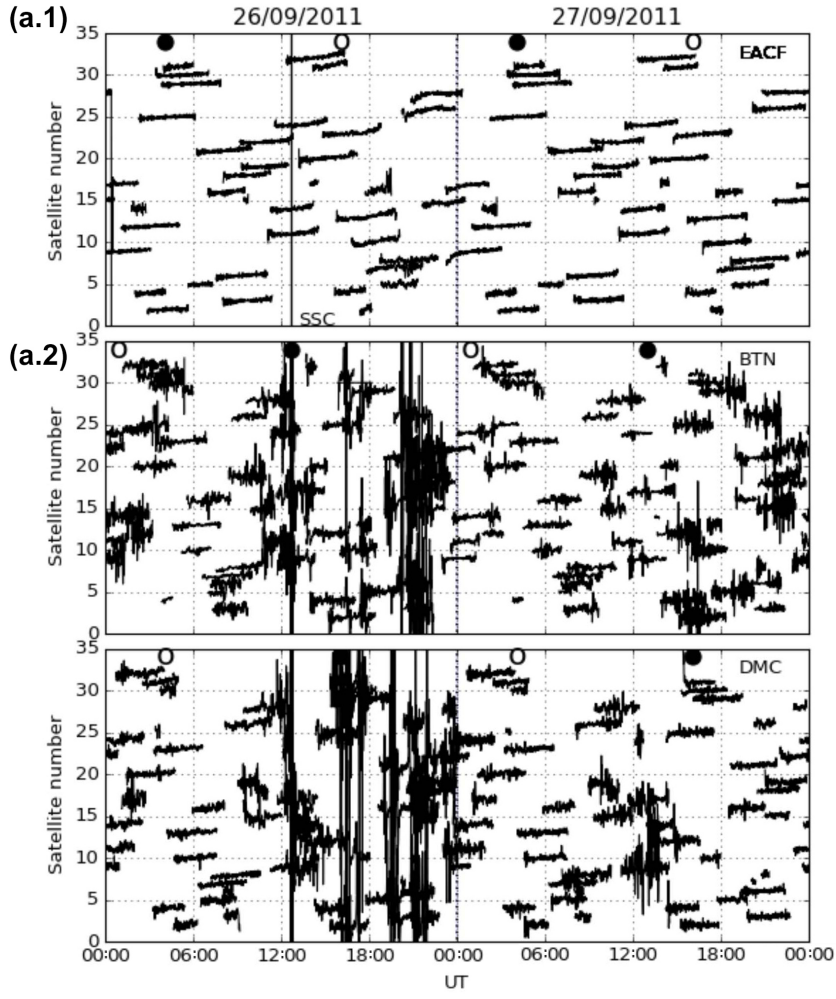

(a)

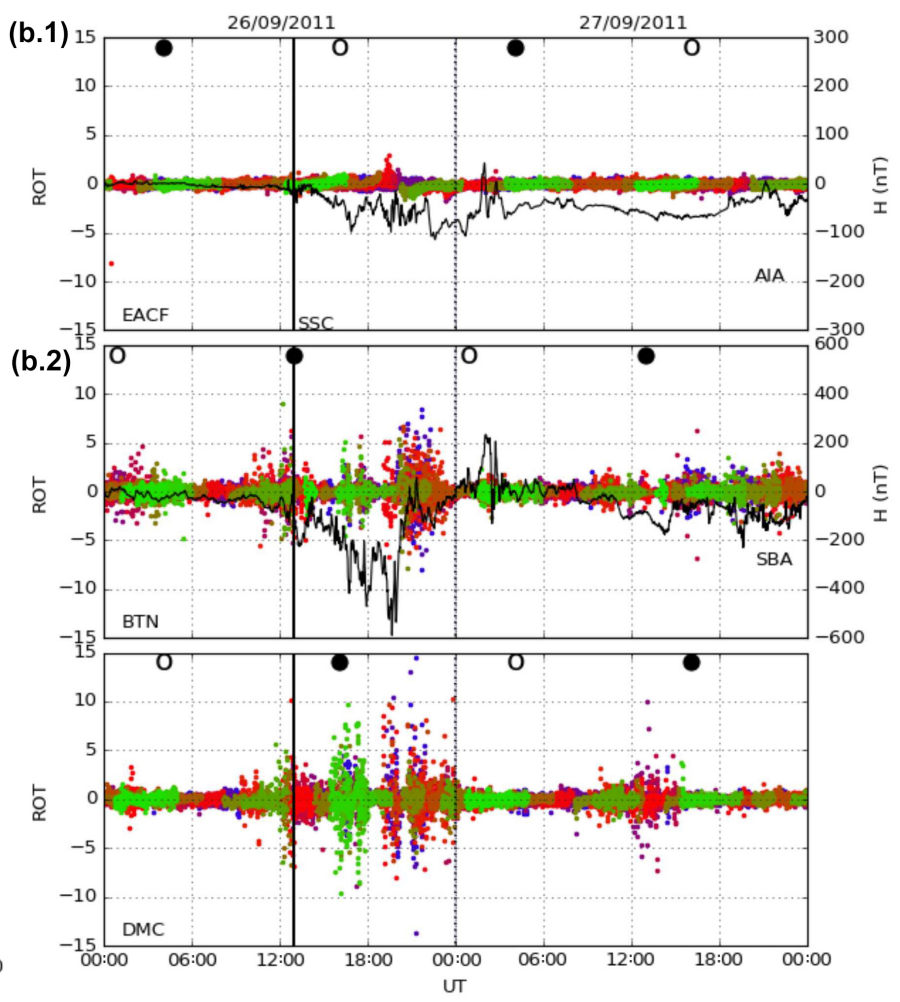

(b)

Figure 4. (a) Variability in ROT values along satellite passes over the midlatitude EACF station in the American sector (a.1) and the polar cap/cusp BTN station and polar cap DMC station, both in the Australian sector (a.2). (b) Time profiles of ROT compared with the H component of surface magnetic field measured at sites near the GNSS station in the American sector (b.1) and in the Australian sector (b.2). The vertical thick line marks the time of the SSC. The open and filled circles refer to local noon and midnight, respectively. ROT is in units of TECU $\min ^{-1}$.

$\sim 60 \%$ at the end of the day. The VTEC parameter from the BTN and DMC stations also shows a similar slow increasing depletion in the polar cap region that started near the geomagnetic storm onset at $\sim 15: 00 \mathrm{UT}$ (near local midnight), reaching $\sim 60 \%$ at the maximum of the geomagnetic storm. Superposed to this VTEC negative slow variation, there are fast increases of $\sim 10 \mathrm{TECU}$. At BTN there is one around $\sim$ 22:00 UT $(\sim 10: 00 \mathrm{LT}$, pre-afternoon sector, near cusp), and at DMC there are two around $\sim$ 17:00 and 19:00 UT (01:00 and 04:00 LT, respectively, in the midnight sector).

During the recovery phase, $N m \mathrm{~F} 2$ and VTEC parameters show that the ionospheric response is very similar at all stations. The parameters stayed at same level of depletion reached at the end of the storm main phase late on 26 September until 12:00 UT (late afternoon at all stations) on 27 September when they slowly returned to QDC values later in the day following the decreasing geomagnetic activity.

\subsection{Ionospheric irregularities}

To analyze the dynamics of high-latitude ionospheric irregularities produced by this geomagnetic storm, we used three GNSS-derived parameters: the rate of TEC (ROT) and the amplitude (S4) and phase $(\sigma \phi)$ scintillation indices, which, when combined, give information about the size scales of irregularities. The analysis is based on the GNSS receivers operating at the EACF (middle-latitude) station located in the Antarctic American sector and at the BTN (cusp/cap) and DMC (polar cap) stations located in the Antarctic Australian sector.

The presence of ionospheric irregularities started to be recorded at $\sim 12: 00$ UT on 26 September, near the time of the SSC, and persisted during the main phase storm until $\sim$ 23:00 UT. The ROT analysis (Fig. 4) shows that the most

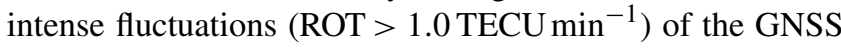
phase signal occurred all night at the BTN and DMC stations (cusp/cap and polar cap regions), while at EACF (middle latitude) it only suggests a slight rise between 19:00 and 22:00 UT (local evening). The scintillation analysis shows that the amplitude of scintillation index S4 (Fig. 5a) has no 


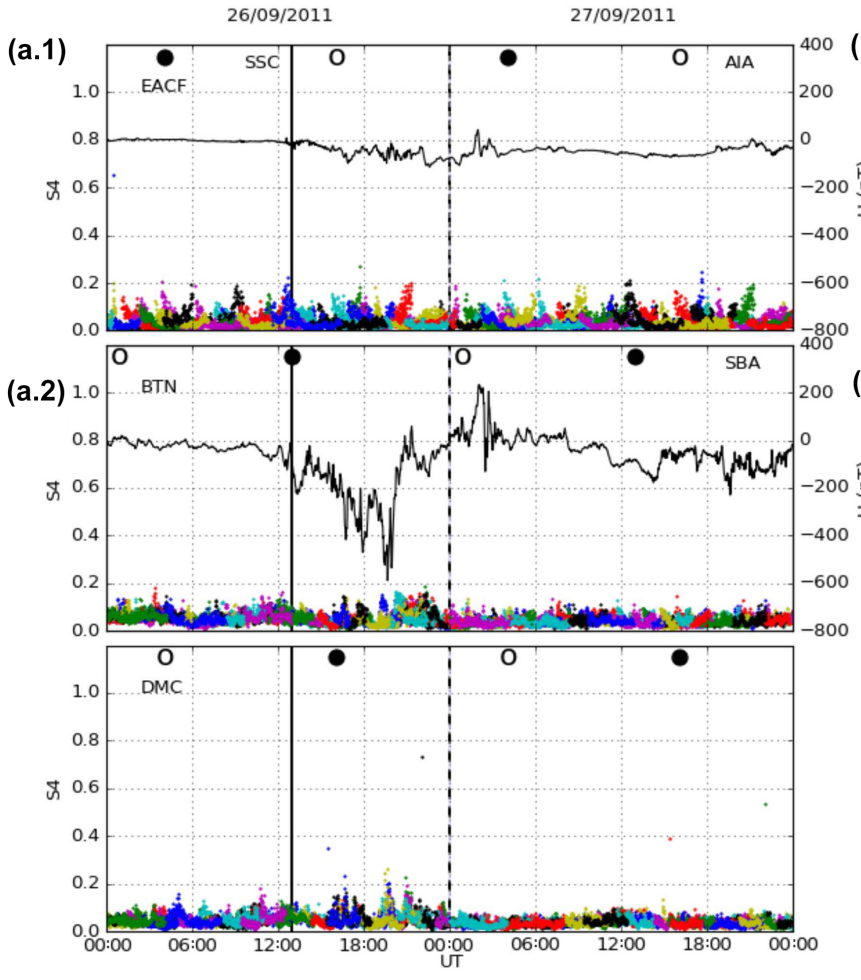

(a)

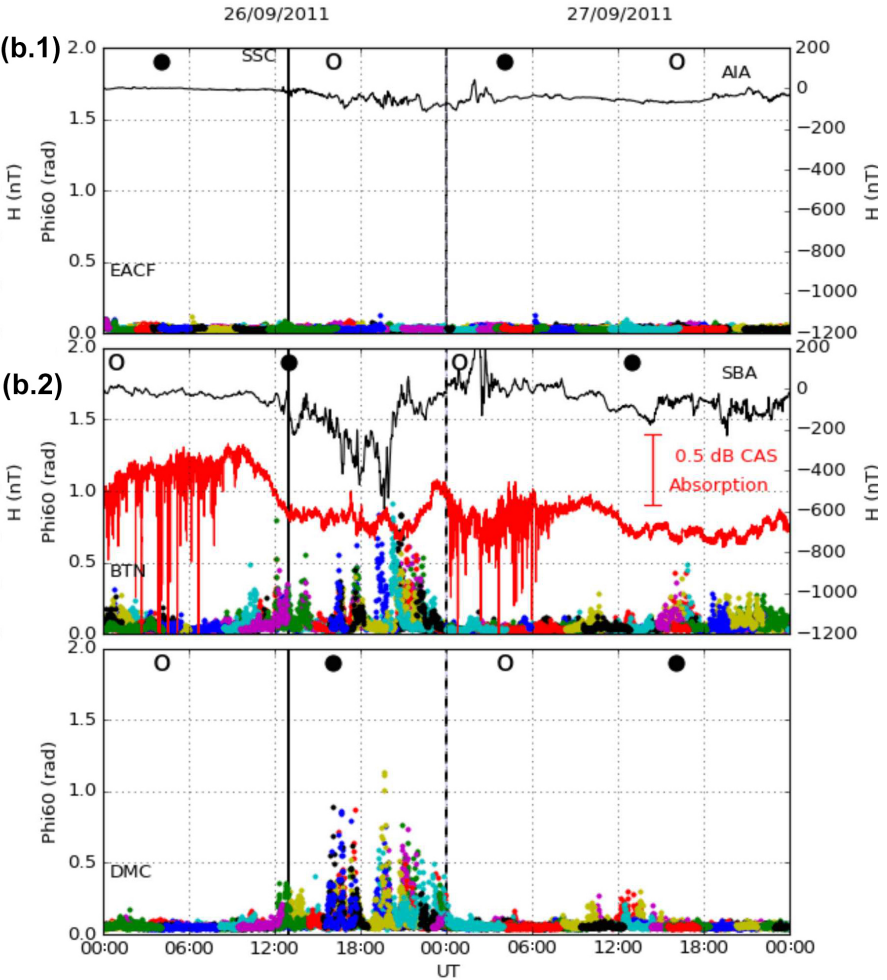

(b)

Figure 5. Variability in scintillation indices $\mathrm{S} 4$ (a) and $\sigma \phi(\mathrm{Phi} 60)$ (b) at the EACF station in the American sector (top panel a.1 and b.1) and at the BTN and DMC stations in the Australian sector (bottom panels a.2 and b.2). Black curves refer to the H component of magnetic field measured at nearby magnetic stations. The red curve refers to cosmic noise absorption measured at the CAS riometer station, which like the BTN station is at the poleward edge of the auroral oval.

significant values above the 0.25 level at EACF and BTN with a significant enhancement only at the DMC station. In contrast, the phase scintillation index $\sigma \phi$ (Phi60 in Fig. 5b) shows strong enhancements, reaching up to $\sim 1.0 \mathrm{rad}$ at the BTN and DMC stations and only $0.2 \mathrm{rad}$ at EACF, which occurred in close association with ROT enhancements. The periods of scintillation enhancements at the BTN station were accompanied by cosmic noise absorptions of $\sim 0.5 \mathrm{~dB}$ measured at the CAS riometer station (Fig. 5b red curve) and fast decreases in the $\mathrm{H}$ component at the nearby SBA geomagnetic station; both are located at the poleward edge of the auroral oval in the Australian sector.

The scintillations observed at the DMC station appeared in four main groups: the first from 12:00 to 15:00 UT during the initial phase of the geomagnetic storm and the other three during the main phase storm from 15:00 to 18:00 UT, 19:00 to 21:00 UT, and 21:00 to 23:00 UT. The three groups of scintillations occurring during the main phase storm have a good association with the density enhancements observed at the middle-latitude stations PST, EACF, and SMA located in the dayside American sector.

The close association of phase scintillation intensification and ROT fluctuations with peaks in HP POES, PCS, and AE indices, as well as with ionospheric absorptions and fast $\mathrm{H}$ component decreases observed near the BTN station indicates that they were produced by ionospheric irregularities caused by energetic particle precipitation in the auroral oval. The stronger enhancements in the phase scintillation rather than in the amplitude index might indicate they are produced by structures with scale sizes higher than one to a few hundred meters (Fresnel scale for L1 signal).

Figure 6 shows the SSUSI image scans mapped in magnetic latitude and MLT at $\sim 13: 53,17: 55,19: 36$, and 20:34 UT, which are representative of four energetic precipitation events that occurred in close association with the phase scintillation enhancements observed at the BTN station. They show the expansion of the auroral oval with the geomagnetic activity since the initial phase (13:53 UT) of the geomagnetic storm until the end of the main phase. The image scan at the initial phase suggests Sun-aligned arcs in the nightside polar cap that might be caused by electron precipitation fluxes with energies of $\sim 3 \mathrm{keV}$ (Newell et al., 2009), which can explain the scintillations observed at the BTN and DMC stations. The other image scans suggest that the strong phase scintillations observed at BTN were produced by irregularities in the auroral oval during its poleward expansion. 


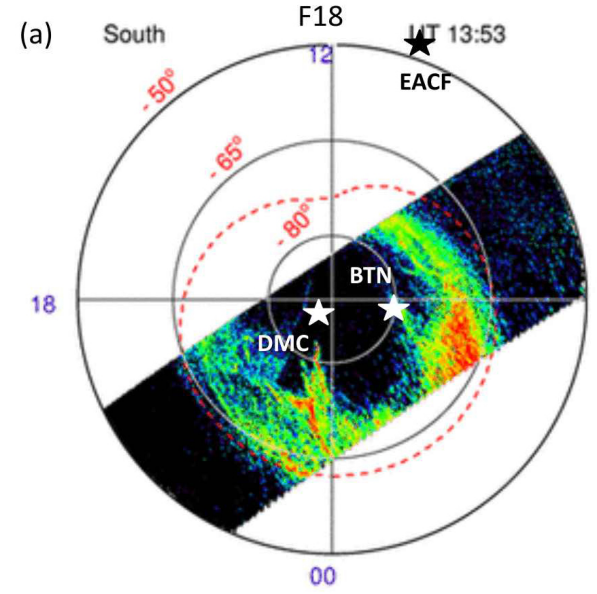

(c)

(c) Sout

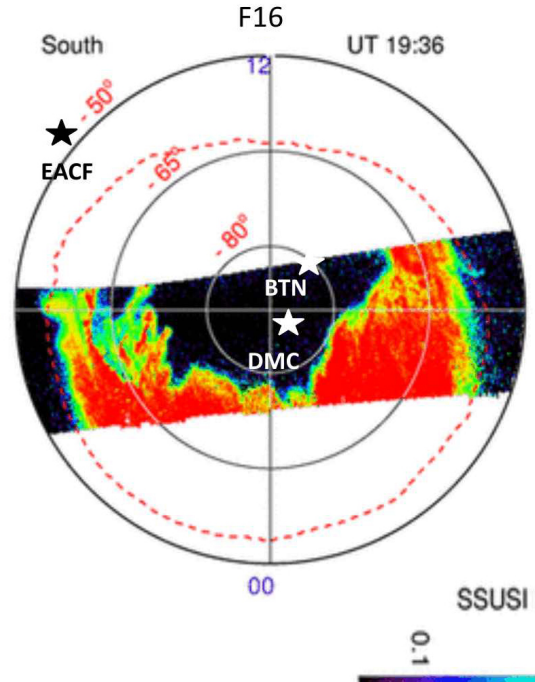

(b)

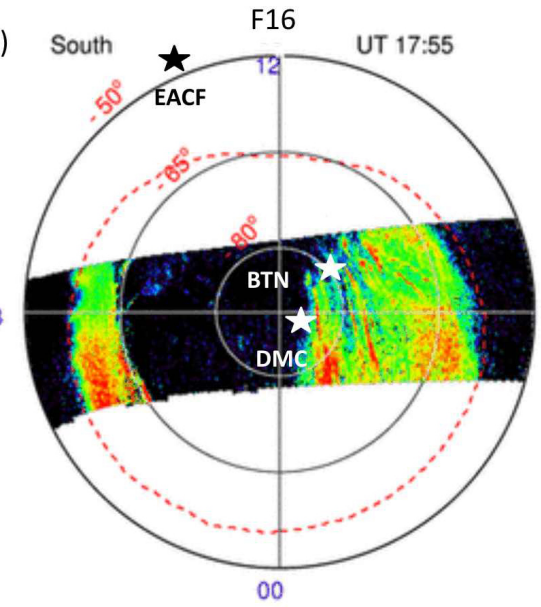

(d)

F18

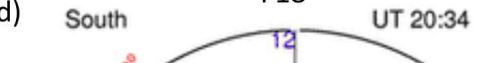

Figure 6. SSUSI (DMSP) southern auroral image scans as a function of magnetic latitude and MLT (http://sd-www.jhuapl.edu/Aurora/) at the (a) initial phase and (b-d) main phase of the geomagnetic storm. The stars mark the locations of the EACF, BTN, and DMC stations.

During the recovery phase of the geomagnetic storm on 27 September, the auroral activity persisted but at lower levels (Fig. 1). The scintillation indices show one significant enhancement at the BTN station between 15:00 and 18:00 UT (post-midnight sector), which occurred in close association with auroral particle precipitation as evidenced by an increase in the HP POES index and SSUSI image scans (not shown).

\section{Discussion and conclusions}

The ionospheric response to the moderately intense geomagnetic storm of 26-27 September 2011 was analyzed at high and middle latitudes in the American and Australian sectors in Antarctica. The ionospheric response was observed on the ground by multiple instruments, such as GNSS receivers, ionosonde, riometers, and magnetometers, which were complemented by an auroral imager on satellites and ground high-frequency radars. The overall results show a complex ionospheric response as a function of the local and storm time.

During the main phase of the geomagnetic storm on 26 September, the observations show a strong positive phase of the ionospheric storm at middle latitudes in the American sector where the geomagnetic storm onset occurred near local noon. $N m \mathrm{~F} 2$ shows a complex evolution with three enhancements accompanied by F2 uplifts. The density enhancements observed at $\sim$ 17:00 and 20:00 UT occurred in association with peaks in the AE and HP-POES indices (Fig. 1), which means close to episodes of energy input into the polar region by energetic particle precipitation in the auroral oval. At the EACF station, the enhancements were seen simultaneously in NmF2 and VTEC but with different amplitudes, which suggests that they were produced by a combination of mechanisms. The positive phase of the ionospheric storm, or storm-enhanced density (SED), observed during 
the afternoon at middle latitudes can be attributed to a superposition of two mechanisms. The first positive storm occurred just after geomagnetic storm onset $(\sim$ 16:00 UT, near local noon time), presenting a stronger electron density increase above the F2-layer maximum. Thus it could be attributed to the predominance of the PPEF effect at middle latitudes. The analysis of the equatorial meridional flows observed on the dayside by the CINDI instrument on the C/NOFS spacecraft showed only excess downward flows at the equatorial region after 17:00 UT, which were attributed to a combined effect of the overshielding and disturbance dynamo processes (Hairston et al., 2014). This behavior could be explained by the effect of the strong IMF $B_{y}$ on the polar cap potential pattern until 19:50 UT along with strong southward $B_{z}$ (Thomas et al., 2013), which reduces the influence of the PPEF at the Equator as suggested by Mannucci et al. (2014). The SEDs observed after 19:00 UT (16:00 LT) might be a combination of PPEF and storm-time convection effects that generate equatorward winds, which lifted the maximum density layer to greater heights at a time when electron production was still operating (e.g., Prolss, 1997; Buonsanto, 1999). These equatorward winds might be associated with traveling atmospheric disturbances (TADs; Prolss and Jung, 1978) generated by impulsive auroral heating. After the dusk effect observed at middle latitude, the ionospheric storm shows an abrupt electron density decrease that is probably associated with the passage of a trough of ionization.

At middle and high latitudes in the Australian sector where the main phase of the geomagnetic storm started during the night and the dawn-to-dusk electric fields are westward, the ionosphere shows only the negative phase (density depletion). The density decrease started just at the onset of the main phase storm almost simultaneously at stations in the auroral oval and polar cap and about $3 \mathrm{~h}$ later at middle-latitude stations. The nighttime negative phase at high and middle latitudes might be dominated by disturbance dynamo processes due to thermosphere heating in the auroral region mainly produced by the Joule dissipation of electric currents (e.g., Seaton, 1956; Prolss, 1995; Buonsanto, 1999), which causes neutral composition changes. The negative phase shows an intensification in the morning sector, probably due to an additional influence of convection effects (Prolss, 1995). Superposed to the slow negative phase observed at the BTN station is a fast VTEC increase at $\sim 23: 00 \mathrm{UT}$, the time at which this station enters the dayside cusp region. At the polar cap DMC station there are two fast VTEC increases at $\sim$ 17:00 and 19:00 UT. These times correspond to periods during which the IMF $B_{z}$ is strongly southward with IMF $B_{y}>0$ (duskward), which are favorable conditions for polar TOI formation (Hosokawa et al., 2010; Thomas et al., 2013). So, these fast VTEC increases might be TOIs originating from SED plumes formed at middle latitudes in the dayside sector (Foster et al., 2004, 2005) that entered the polar cap through the cusp.
To investigate SED-TOI formation over Antarctica, we considered GPS TEC maps with SuperDARN convection patterns overlaid (Fig. 7). Despite the low GPS network coverage in the Southern Hemisphere, the GPS TEC maps at $\sim$ 16:40, 19:30 and 20:50 UT (Fig. 7b-d) suggest SED plumes at middle latitudes in the American sector (dayside). The SED plumes have a good association with the middlelatitude TEC enhancements observed at EACF and the fast ones observed at the polar cap DMC station (nightside), suggesting that they enter the polar cap region trough the dayside cusp as a TOI. The strong phase scintillations observed at the cusp/cap BTN and polar cap DMC stations occurred in close association with the fast TEC enhancements and ionospheric backscatter observed in the SuperDARN LOS velocity measurements (Fig. 7e-h) taken in the polar cap region. The results show that during the main phase storm the scintillations were collocated with antisunward convection and TOI originating from dayside SED (Fig. $7 \mathrm{f}$ and g). Strong scintillations were also observed at the BTN and DMC stations between $\sim 21: 00$ and 23:00 UT when the IMF almost returned to quiet conditions with IMF $B_{z}$ and $B_{y}$ nearly zero. They occurred in close association with TEC enhancement at the BTN station, which enters the dayside cusp from which a TOI was drawn into the polar cap, as confirmed by ionospheric backscatter observed in the polar cap region by SuperDARN radars (not shown).

The ionospheric response in the Northern Hemisphere to this geomagnetic storm was reported by Thomas et al. (2013), who show that a linked SED-TOI event occurred between 18:30 and 19:40 UT and a lack of TOI associated with the SED period from 20:30 to 24:00 UT. The SEDTOI event has a counterpart in the Southern Hemisphere, but contrary to their SED results with no TOI, in Antarctica we have a TOI formation. This difference in the ionospheric response can be explained by interhemispheric asymmetry due to the high-latitude coupling between solar wind and the magnetosphere. This asymmetry drives the dawn-dusk component of the interplanetary magnetic field that defines the cusp location and thus determines whether the stormenhanced density plasma will enter the polar cap and the orientation of the antisunward convection in the polar cap relative to the noon-midnight meridian (Cherniak et al., 2015; Horvarth and Lovell, 2015; Prikryl et al., 2013, 2015b).

During the initial phase of the geomagnetic storm, a group of GNSS scintillations was observed at the polar cap DMC station between $\sim 12: 40$ and 15:00 UT, which also has an ionospheric backscatter counterpart in polar cap region (Fig. 7e). Since they occurred under northward IMF $B_{z}$ conditions, these scintillations might be produced by polar cap irregularities associated with transpolar Sun-aligned arcs, as evidenced by the SSUSI (DMSP F18) auroral image over Antarctica obtained at 13:53 UT (Fig. 6a), which is in agreement with Newell et al. (2009) and Prikryl et al. (2015a, b). 
(a)

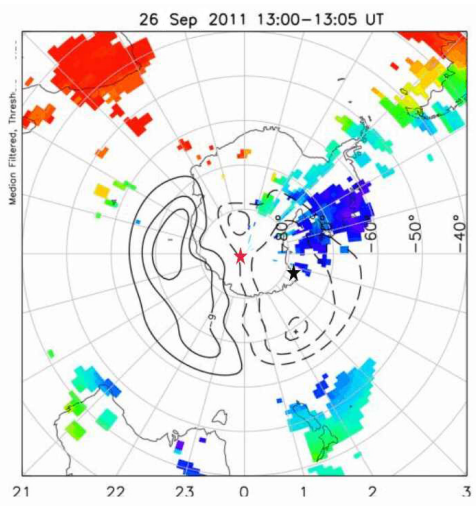

(b)

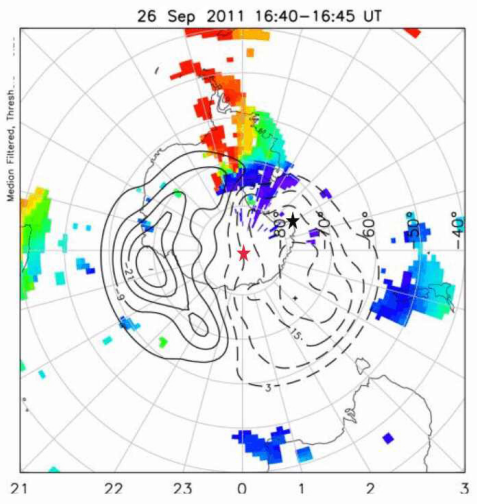

(c)

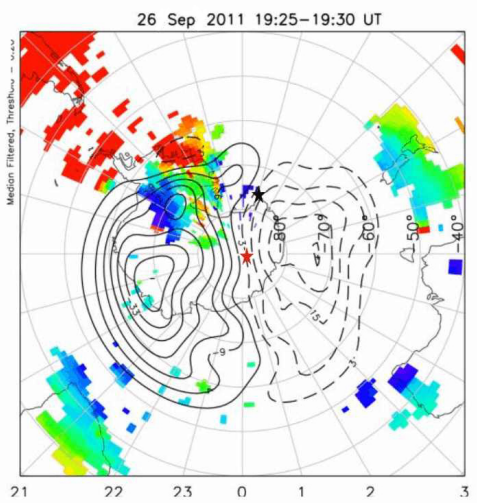

(d)

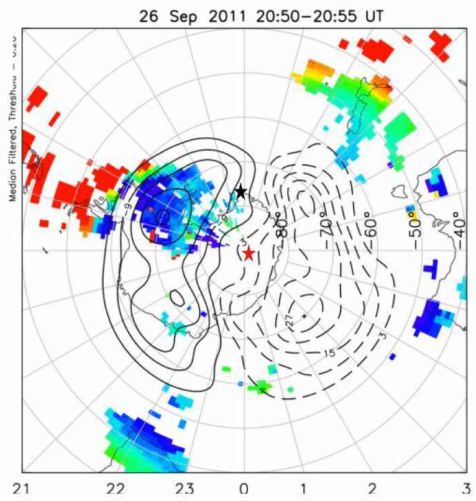

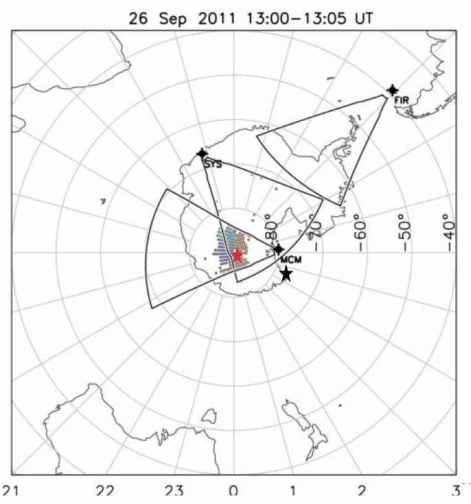

(e)

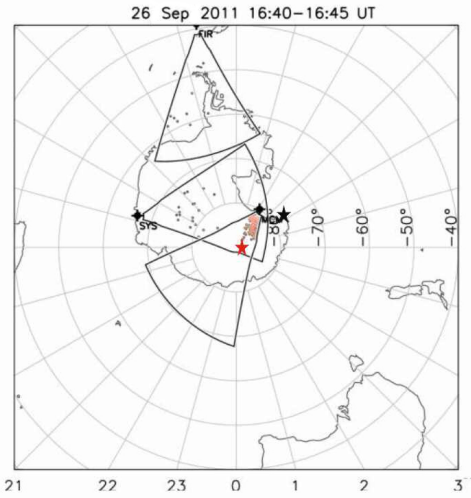

(f)

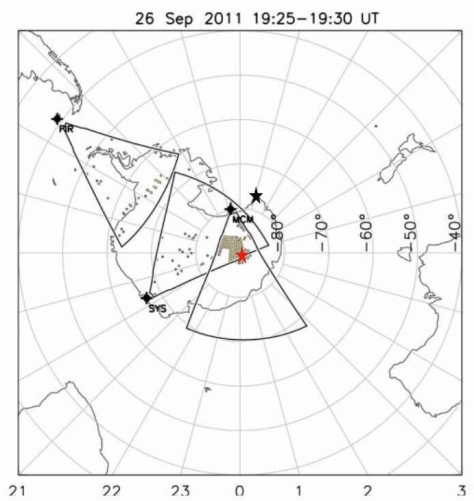

(g)

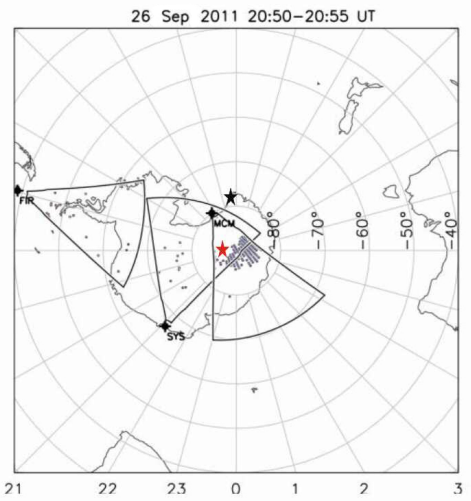

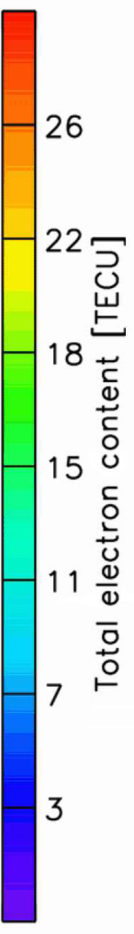

(h)

Figure 7. (a-d) GPS TEC maps of storm-enhanced density (SED) episodes during the main phase of the geomagnetic storm with SuperDARN convection patterns overlaid. (e-h) SuperDARN LOS velocity measurements from ionospheric scatter for selected radars. Figures are in magnetic latitude and MLT with magnetic noon at the top for times 13:00, 16:40, 19:25, and 20:50 UT. The stars mark the BTN (black) and DMC (red) station locations. 
A schematic of the ionospheric processes associated with this moderately strong geomagnetic storm at middle and high latitudes in the Southern Hemisphere is as follows: during the main phase of the geomagnetic storm, the PPEF penetrates both the dayside and nightside ionosphere. On the dayside, the normal eastward dawn-to-dusk electric field is reinforced by the PPEF lifting the equatorial ionospheric plasma to higher altitudes and latitudes, forming the so-called dayside ionospheric superfountain (DIS) effect (Tsurutani et al., 2004). The DIS results in an overall dayside ionospheric electron density increase with EIA crests reaching midlatitudes, which might account for the stronger TEC enhancement compared to the $N m \mathrm{~F} 2$ density increase observed at the middle-latitude stations PST, EACF, and SMA during the first 2 hours of the main phase geomagnetic storm. In the following, the TEC and $N m \mathrm{~F} 2$ show similar increases, suggesting that the positive storm at midlatitudes was dominated by the disturbance dynamo processes up to the end of the main phase storm. On the nightside during the main phase storm, from middle to high latitudes the westward dawnto-dusk electric fields are dominated by the dynamo disturbance, causing a downward plasma drift, which increases the recombination and decreases the electron density.

In conclusion, this paper shows the middle- and highlatitude ionospheric response during the 26-27 September 2011 moderately intense geomagnetic storm in Antarctica. The multi-instrument observations permitted us to characterize the ionospheric response as a function of storm time and location in the American and Australian sectors in Antarctica and compare these results with the ones reported in the Northern Hemisphere to complete the picture of this storm in the interhemispheric context. The analysis shows that the ionosphere was highly structured and dynamic as a consequence of solar wind coupling with the magnetosphere-ionospheric system, suggesting a combination of effects associated with PPEFs and disturbance dynamo processes. Storm-density enhancements (SEDs) are observed at middle latitudes in the dayside sector just after the onset of the main phase storm, suggesting that they are due to the influence of electrodynamical processes associated with PPEF; however, after a couple of hours they might be dominated by storm-time disturbance dynamo processes. The depletion density observed from middle to high latitudes in the nightside sector are due to the westward direction of the dawn-to-dusk electric fields, which cause the ionospheric plasma to drift downward, increasing the recombination processes. The ionospheric irregularities that are responsible for the strong GNSS scintillations and ionospheric backscatter were observed (a) during the initial phase of the geomagnetic storm in association with transpolar Sun-aligned arcs and (b) during the main phase storm collocated with SED plumes at middle latitudes and cusp on the dayside, with the auroral oval during energetic particle precipitation events, and with the polar cap TOI features observed on the nightside under different periods of IMF conditions. Two SED-
TOI formations were observed during the main phase storm in association with disturbance dynamo processes at high latitudes in Antarctica. The second one, which occurred at the end of the main phase storm, has no counterpart in the geomagnetically conjugate location in the Northern Hemisphere, which can be attributed to interhemispheric asymmetry due to the IMF dawn-dusk component. In the Southern Hemisphere the IMF was in the dawnward direction, which drives the SED plasma in the cusp direction, forming the TOI in the polar cap. In the Northern Hemisphere it was in the duskward direction, which drives the SED away from the cusp and no polar TOI is formed. Thus, the formation of polar TOI is a function of the SED plume location and local electric field action, which might be nearby and in the direction of the dayside cusp from which it can enter the polar cap.

Data availability. The solar wind and interplanetary magnetic field (IMF) data were obtained from the ACE/SWEPAM and OMNIWeb data services (http://www.srl.caltech.edu/ACE/ASC/level2/ lvl2DATA_MAG-SWEPAM.html, http://omniweb.gsfc.nasa.gov). The geomagnetic indices were obtained from the World Data Center for Geomagnetism, Kyoto (http://wdc.kugi.kyoto-u.ac.jp/wdc/ Sec3.html). The polar cap index is derived using the magnetic data of Vostok (http://pcindex.org/about-3). NOAA POES Hemispheric Power data was obtained from the Space Weather Prediction Center of NOAA (http://legacy-www.swpc.noaa.gov/ftpdir/lists/hpi). The ionospheric parameters from ionosondes operating at the PST, $\mathrm{HOB}$, and MCI stations were obtained from the Space Physics Interactive Data Resource (SPIDR; http://spidr.ionosonde.net/spidr). The cosmic noise absorption (CNA) measured at Casey Station was obtained from the World Data Centre Space Weather Services (SWS, formally known as IPS Radio and Space Services or IPS; http://www.sws.bom.gov.au). The surface magnetic field was obtained from the INTERMAGNET database (http://www. intermagnet.org; St-Louis et al., 2012). The energy flux and mean energy of precipitated energetic particles were obtained from the Special Sensor Ultraviolet Scanning Imager (SSUSI) onboard the Defense Meteorological Satellite Program (DMSP) satellites (https: //ssusi.jhuapl.edu). The TEC maps were obtained using the plotting tools available online at the Space@VT SuperDARN website (http://vt.superdarn.org). The TEC data were downloaded through the Madrigal database at Haystack Observatory. The GNSS and ionosonde data from EACF station are available upon request from the corresponding author at ecorreia@craam.mackenzie.br. The GNSS data from the DMC and BTN stations are available upon request from the author Luca Spogli at luca.spogli@ingv.it, and the ionosonde data from San Martin Base from the author Adriana Gulisano are available at adrianagulisano@gmail.com.

Competing interests. The authors declare that they have no conflict of interest.

Special issue statement. This article is part of the special issue "Space weather connections to near-Earth space and the atmosphere". It is a result of the $6^{\circ}$ Simpósio Brasileiro de Geofísica 
Espacial e Aeronomia (SBGEA), Jataí, Brazil, 26-30 September 2016.

Acknowledgements. Emilia Correia thanks the National Council for Research and Development $(\mathrm{CNPq})$ for individual research support (process nos. 556872/2009-6, 406690/2013-8, and 306142/2013-9) and the National Institute for Space Research (INPE/MCTI). The authors also acknowledge the support of the Brazilian Ministry of Science, Technology and Innovation (MCTI), the Ministry of the Environment (MMA), and the Inter-Ministry Commission for Sea Resources (CIRM). This work integrates the National Institute of Science and Technology Antarctic Environmental Research (INCTAPA) under scientific and financial support from the CNPq (process no. 574018/2008-5) and the Carlos Chagas Research Support Foundation of the State of Rio de Janeiro (FAPERJ no. E16/170.023/2008). DMC and BTN data have been acquired in the framework of the projects PNRA14_00133 and PNRA14_00110. The authors acknowledge the GRAPE Expert Group endorsed by SCAR to facilitate the collaboration (http://www.grape.scar.org/). The DMSP particle detectors were designed by Dave Hardy of the Air Force Research Laboratory, and the data were obtained from the Johns Hopkins University Applied Research Laboratory (http: //ssusi.jhuapl.edu). The TEC maps were obtained using the plotting tools available online at the Space@VT SuperDARN website (http://vt.superdarn.org). The TEC data were downloaded through the Madrigal database at Haystack Observatory. The authors acknowledge the use of SuperDARN data. SuperDARN is a collection of radars funded by the national scientific funding agencies of Australia, Canada, China, France, Japan, South Africa, the UK, and the United States of America. The authors also thank the two anonymous referees for their valuable comments and suggestions.

The topical editor, Jean-Pierre Raulin, thanks two anonymous referees for help in evaluating this paper.

\section{References}

Aarons, J., Lin, B., Mendillo, M., Liou, K., and Codrescu, M.: Global Positioning System phase fluctuations and ultraviolet images from the Polar satellite, J. Geophys. Res., 105, 5201-5213, https://doi.org/10.1029/1999JA900409, 2000.

Alfonsi, L., Spogli, L., De Franceschi, G., Romano, V., Aquino, M., Dodson, A., and Mitchell, C. N.: Bipolar climatology of GPS ionospheric scintillation at solar minimum, Radio Sci., 46, RS0D05, https://doi.org/10.1029/2010RS004571, 2011.

Balan, N. and Bailey, G. J.: Equatorial plasma fountain and its effects: possibility of an additional layer, J. Geophys. Res.-Space, 100, 21421-21432, https://doi.org/10.1029/95JA01555, 1995.

Blanc, M. and Richmond, A. D.: The ionospheric disturbance dynamo, J. Geophys. Res.-Space, 85, 1669-1686, 1980.

Buonsanto, M. J.: Ionospheric storms - a review, Space Sci. Rev., 88, 563-601, 1999.

Cherniak, I., Zakharenkova, I., and Redmon, R. J.: Dynamics of the high-latitude ionospheric irregularities during the 17 March 2015 St. Patrick's Day storm: ground-based GPS measurements, Space Weather, 13, 585-597, https://doi.org/10.1002/2015SW001237, 2015.
Chisham, G., Lester, M., Milan, S. E., Freeman, M. P., Bristow, W. A., Grocott, A., McWilliams, K. A., Ruohoniemi, J. M., Yeoman, T. K., Dyson, P. L., Greenwald, R. A. Kikuchi, T., Pinnock, M., Rash, J. P., Sato, S., Sofko, G. J., Villain, J.P., and Walker, A. D. M.: A decade of the Super Dual Auroral Radar Network (SuperDARN): scientific achievements, new techniques and future directions, Surv. Geophys., 28, 33-109, https://doi.org/10.1007/s10712-007-9017-8, 2007.

Ciraolo, L., Azpilicueta, F., Brunini, C., Meza, A., and Radicella, S. M.: Calibration errors on experimental slant total electron content (TEC) determined with GPS, J. Geodesy, 81, 111120, https://doi.org/10.1007/s00190-006-0093-1, 2007.

Danilov, A. D.: Ionospheric F-region response to geomagnetic disturbances, Adv. Space Res., 52, 343-366, 2013.

Danilov, A. D. and Lastovicka, J.: Effects of geomagnetic storms on the ionosphere and atmosphere, Int. J. Geomagnetic Aeronomy, 2, 209-224, 2001.

De Franceschi, G., Alfonsi, L., Romano, V., Aquino, M. H. O., Dodson, A., Mitchell, C. N., and Wernik, A. W.: Dynamics of high latitude patches and associated small scale irregularities, J. Atmos. Sol.-Terr. Phy., 70, 879-888, https://doi.org/10.1016/j.jastp.2007.05.018, 2008.

Fagundes, P. R., Pillat, V. G., Bolzan, M. J. A., Sahai, Y., BeckerGuedes, F., Abalde, J. R., Aranha, S. L., and Bittencourt, J. A.: Observations of F-layer electron density profiles modulated by pw type oscillations in the equatorial ionospheric anomaly region, J. Geophys. Res.-Space, 110, 1-8, 2005.

Fejer, B. G., Spiro, R. W., Wolf, R. A., and Foster, J. C.: Latitudinal variation of perturbation electric fields during magnetically disturbed periods: 1986 SUNDIAL observations and model results, Ann. Geophys., 8, 441-454, 1990.

Foster, J. C.: Storm-time plasma transport at middle and high latitudes, J. Geophys. Res., 98, 1675-1689, 1993.

Foster, J. C.: Ionospheric-magnetospheric-heliospheric coupling: Storm-time thermal plasma redistribution, in Mid-Latitude Dynamics and Disturbances, Geophys. Monogr. Ser., vol. 181, edited by: Kintner, P. M., Coster, A. J., Fuller-Rowell, T., Mannucci, A. J., Mendillo, M., and Heelis, R., AGU, Washington, D. C., https://doi.org/10.1029/181GM12, 121-134, 2008.

Foster, J. C. and Burke, W. J.: SAPS: a new characterization for sub-auroral electric fields, EOS T. Am. Geophys. Un., 83, 393, https://doi.org/10.1029/2002EO000289, 2002.

Foster, J. C., Coster, A. J., Erickson, P. J., Rich, F. J., and Sandel, B. R.: Storm time observations of the flux of plasmaspheric ions to the dayside cusp/magnetopause, Geophys. Res. Lett., 31, L08809, https://doi.org/10.1029/2004GL020082, 2004.

Foster, J. C., Coster, A. J., Erickson, P. J., Holt, J. M., Lind, F. D., Rideout, W., McCready, M., van Eyken, A., Barnes, R. J., Greenwald, R. A., and Rich, F. J.: Multiradar observations of the polar tongue of ionization, J. Geophys. Res.-Space, 110, A09S31, https://doi.org/10.1029/2004JA010928, 2005.

Fuller-Rowell, T. J., Codrescu, M. V., Moffett, R. J., and Quegan, S.: Response of the thermosphere and ionosphere to geomagnetic storms, J. Geophys. Res.-Space, 99, 3893-3914, 1994.

Gonzalez, W. D., Tsurutani, B. T., Gonzalez, A. L. C., Smith, E. J., Tang, F., and Akasofu, S. I.: Solar wind-magnetosphere coupling during intense magnetic storms (1978-1979), J. Geophys. Res.Space, 94, 8835-8851, 1989. 
Gonzalez, W. D., Joselyn, J. A., Kamide, Y., Kroehl, H. W., Rostoker, G., Tsurutani, B. T., and Vasyliunas, V. M.: What is a geomagnetic storm?, J. Geophys. Res.-Space, 99, 5771-5792, 1994.

Gonzalez, W. D., Tsurutani, B. T., and Gonzalez, A. L. C.: Interplanetary origin of geomagnetic storms, Space Sci. Rev., 88, 529-562, https://doi.org/10.1023/A:1005160129098, 1999.

Greenwald, R. A., Baker, K. B., Dudeney, J. R., Pinnock, M., Jones, T. B., Thomas, E. C., Villain, J.-P., Cerisier, J.-C., Senior, C., Hanuise, C., Hunsucker, R. D., Sofko, G., Koehler, J., Nielsen, E., Pellinen, R., Walker, A. D. M., Sato, N., and Yamagishi, H.: DARN/SUPERDARN: a global view of the dynamics of highlatitude convection, Space Sci. Rev., 71, 761-796, 1995.

Hairston, M., Maruyama, N., Coley, W. R., and Stoneback, R.: Storm-time meridional flows: a comparison of CINDI observations and model results, Ann. Geophys., 32, 659-668, https://doi.org/10.5194/angeo-32-659-2014, 2014.

Horvath, I. and Lovell, B. C.: Storm-enhanced plasma density and polar tongue of ionization development during the 15 May 2005 superstorm, J. Geophys. Res.-Space, 120, 5101-5116, https://doi.org/10.1002/2014JA020980, 2015.

Hosokawa, K., Tsugawa, T., Shiokawa, K., Otsuka, Y., Nishitani, N., Ogawa, T., and Hairston, M. R.: Dynamic temporal evolution of polar cap tongue of ionization during magnetic storm, J. Geophys. Res.-Space, 115, 333, https://doi.org/10.1029/2010JA015848, 2010.

Huang, C.-S., Foster, J. C., and Kelley, M. C.: Longduration penetration of the interplanetary electric field to the low-latitude ionosphere during the main phase of magnetic storms, J. Geophys. Res.-Space, 110, A11309, https://doi.org/10.1029/2005JA011202, 2005.

Kan, J. R. and Lee, L. C.: Energy coupling function and solar windmagnetosphere dynamo, Geophys. Res. Lett., 6, 577-580, 1979.

Kelley, M. C., Makela, J. J., Chau, J. L., Nicolls, M. J.: Penetration of the solar wind electric field into the magnetosphere/ionosphere system, Geophys. Res. Lett., 30, 1158, https://doi.org/10.1029/2002GL016321, 2003.

Kinrade, J., Mitchell, C. N., Smith, N. D., Ebihara, Y., Weatherwax, A. T., and Bust, G. S.: GPS phase scintillation associated with optical auroral emissions: first statistical results from the geographic South Pole, J. Geophys. Res.-Space, 118, 2490-2502, https://doi.org/10.1002/jgra.50214, 2013.

Kintner, P. M., Ledvina, B. M., and de Paula, E. R.: GPS and ionospheric scintillations, Space Weather, 5, S09003, https://doi.org/10.1029/2006SW000260, 2007.

Lastovicka, J.: Effects of geomagnetic storms in the lower ionosphere, middle atmosphere and troposphere, J. Atmos. Terr. Phys., 58, 831-843, 1996.

Li, G., Ning, B., Ren, Z., and Hu, L.: Statistics of GPS ionospheric scintillation and irregularities over polar regions at solar minimum, GPS Solut., 14, 331-341, https://doi.org/10.1007/s10291009-0156-x, 2010.

Mannucci, A. J., Wilson, B. D., and Edwards, C. D.: A new method for monitoring the Earth's ionospheric total electron content using the GPS global network, in: Proceedings of ION GPS-93, the 6th International Technical Meeting of the Satellite Division of The Institute of Navigation, Salt Lake City, UT, 22-24 September, The Institute of Navigation, Alexandria, VA, 1323-1332, 1993.
Mannucci, A. J., Tsurutani, B. T., Iijima, B. A. , Komjathy, A., Saito, A., Gonzalez, W. D., Guarnieri, F. L., Kozyra, J. U., and Skoug, A.: Dayside global ionospheric response to the major interplanetary events of October 29-30, 2003 "Halloween Storms", Geophys. Res. Lett., 32, L12S02, https://doi.org/10.1029/2004GL021467, 2005.

Mannucci, A. J., Tsurutani, B. T., Abdu, M. A., Gonzalez, W. D., Komjathy, A., Echer, E., Iijima, B. A., Crowley, G., and Anderson, D.: Superposed epoch analysis of the dayside ionospheric response to four intense geomagnetic storms, J. Geophys. Res.Space, 113, A00A02, https://doi.org/10.1029/2007JA012732, 2008.

Mannucci, A. J., Crowley, G., Tsurutani, B. T., Verkhoglyadova, O. P., Komjathy, A., and Stephens, P.: Interplanetary magnetic field by control of prompt total electron content increases during superstorms, J. Atmos. Sol.-Terr. Phy., 115-116, 7-16, https://doi.org/10.1016/j.jastp.2014.01.001, 2014.

Mansilla, G. A.: Thermosphere-ionosphere response at middle and high latitudes during perturbed conditions: a case study, J. Atmos. Sol.-Terr. Phy., 70, 1448-1454, 2008.

Mendillo, M.: Storms in the ionosphere: Patterns and processes for total electron content, Rev. Geophys., 44, 1-47, https://doi.org/10.1029/2005RG000193, 2006.

Mendillo, M., Papagiannis, M. D., and Klobuchar, J. A.: Ionospheric storms at midlatitudes, Radio Sci., 5, 895-898, 1970.

Mikhailov, A. V. and Foster, J. C.: Daytime thermosphere above Millstone Hill during severe geomagnetic storms, J. Geophys. Res.-Space, 102, 17275-17282, 1997.

Newell, P. T., Liou, K., and Wilson, G. R.: Polar cap particle precipitation and aurora: review and commentary, J. Atmos. Sol.-Terr Phy., 71, 199-215, 2009.

Nishida, A.: Coherence of geomagnetic DP2 fluctuations with interplanetary magnetic variations, J. Geophys. Res.-Space, 73, 5549-5559, 1968.

Paxton, L. J., Morrison, D., Zhang, Y., Kil, H., Wolven, B., Ogorzalek, B. S., Humm, D. C., and Meng, C.-I.: Validation of remote sensing products produced by the Special Sensor Ultraviolet Scanning Imager (SSUSI) - a farUV imaging spectrograph on DMSP F16, Proc. SPIE, 4485, https://doi.org/10.1117/12.454268,, 2002.

Prikryl, P., Spogli, L., Jayachandran, P. T., Kinrade, J., Mitchell, C. N., Ning, B., Li, G., Cilliers, P. J., Terkildsen, M., Danskin, D. W., Spanswick, E., Donovan, E., Weatherwax, A. T., Bristow, W. A., Alfonsi, L., De Franceschi, G., Romano, V., Ngwira, C. M., and Opperman, B. D. L.: Interhemispheric comparison of GPS phase scintillation at high latitudes during the magnetic-cloud-induced geomagnetic storm of 5-7 April 2010, Ann. Geophys., 29, 2287-2304, https://doi.org/10.5194/angeo29-2287-2011, 2011.

Prikryl, P., Ghoddousi-Fard, R., Kunduri, B. S. R., Thomas, E. G., Coster, A. J., Jayachandran, P. T., Spanswick, E., and Danskin, D. W.: GPS phase scintillation and proxy index at high latitudes during a moderate geomagnetic storm, Ann. Geophys., 31, 805816, https://doi.org/10.5194/angeo-31-805-2013, 2013a.

Prikryl, P., Zhang, Y., Ebihara, Y., Ghoddousi-Fard, R., Jayachandran, P. T., Kinrade, J., Mitchell, C. N., Weatherwax, A. T., Bust, G., Cilliers, P. J., Spogli, L., Alfonsi, L., De Franceschi, G., Romano, V., Ning, B., Li, G., Jarvis, M. J., Danskin, D. W., Spanswick, E., Donovan, E., and Terkildsen, M.: An interhemispheric 
comparison of GPS phase scintillation with auroral emission observed at South Pole and from DMSP satellite, Special Issue of Ann. Geophys.-Italy, 56, R0216, https://doi.org/10.4401/ag6227, 2013b.

Prikryl, P., Ghoddousi-Fard, R., Thomas, E. G., Ruohoniemi, J. M., Shepherd, S. G., Jayachandran, P. T., Danskin, D. W., Spanswick, E., Zhang, Y., Jiao, Y., and Morton, Y. T.: GPS phase scintillation at high latitudes during geomagnetic storms of 7-17 March 2012 - Part 1: The North American sector, Ann. Geophys., 33, 637656, https://doi.org/10.5194/angeo-33-637-2015, 2015a.

Prikryl, P., Ghoddousi-Fard, R., Spogli, L., Mitchell, C. N., Li, G., Ning, B., Cilliers, P. J., Sreeja, V., Aquino, M., Terkildsen, M., Jayachandran, P. T., Jiao, Y., Morton, Y. T., Ruohoniemi, J. M., Thomas, E. G., Zhang, Y., Weatherwax, A. T., Alfonsi, L., De Franceschi, G., and Romano, V.: GPS phase scintillation at high latitudes during geomagnetic storms of 7-17 March 2012 - Part 2: Interhemispheric comparison, Ann. Geophys., 33, 657-670, https://doi.org/10.5194/angeo-33-657-2015, 2015b.

Prikryl, P., Ghoddousi-Fard, R., Weygand, J. M., Viljanen, A., Connors, M., Danskin, D. W., Jayachandran, P. T., Jacobsen, K. S., Andalsvik, Y. L., Thomas, E. G., Ruohoniemi, J. M., Durgonics, T., Oksavik, K., Zhang, Y., Spanswick, E., Aquino, M., and Sreeja, V.: GPS phase scintillation at high latitudes during the geomagnetic storm of 17-18 March 2015, J. Geophys. Res.-Space, 121, 10448-10465, https://doi.org/10.1002/2016JA023171, 2016.

Prolss, G. W.: Ionospheric F-region storms, in: Handbook of Atmospheric Electrodynamics, vol. 2, edited by: Volland, H., chap. 8, CRC Press, Boca Raton, FL, 195-248, 1995.

Prolss, G. W.: Magnetic storm associated perturbations of the upper atmosphere, in Magnetic Storms, vol. 98, edited by: Tsurutani, B. T., Gonzalez, W. D., Kamide Y.,, and Arballo, J. K., 227 pp., AGU, Washington, D. C., USA, 1997.

Prolss, G. W.: Ionospheric storms at mid-latitude: a short review, In: Midlatitude Ionospheric Dynamics and Disturbances, Geoph. Monog. Series, 181, 9-24, https://doi.org/10.1029/181GM03, 2008.

Prolss, G. W. and Jung, M. J.: Travelling atmospheric disturbances as a possible explanation for daytime positive storm effects of moderate duration at middle latitudes, J. Atmos. Terr. Phys., 40, 1351-1354, 1978.

Rideout, W. and Coster, A.: Automated GPS processing for global total electron content data, GPS Solut., 10, 219-228, https://doi.org/10.1007/s10291-006-0029-5, 2006.

Sandel, B. R., King, R. A., Forrester, W. T., Gallagher, D. L., Broadfoot, A. L., and Curtis, C. C.: Initial results from the IMAGE extreme ultraviolet imager, Geophys. Res. Lett., 28, 1439-1442, 2001.

Sastri, J. H.: Equatorial electric fields of the disturbance dynamo origin, Ann. Geophys., 6, 635-642, 1988.

Seaton, M. J.: A possible explanation of the drop in F-region critical densities accompanying many ionospheric storms, J. Atmos. Terr. Phys., 8, 122-124, 1956.

Senior, C. and Blanc, M.: On the control of magnetospheric convection by the spatial distribution of ionospheric conductivities, J. Geophys. Res., 89, 261-284, 1984.

Skone, S., Man, F., Ghafoori, F., and Tiwari, R.: Investigation of scintillation characteristics for high latitude phenomena, ION GNSS 2008, Session D5, Savannah, GA, 16-19 September 2008.
Spiro, R. W., Wolf, R. A., and Fejer, B. G.: Penetration of high latitude electric field effects to low latitudes during SUNDIAL 1984, Ann. Geophys., 6, 39-49, 1988.

Spogli, L., Alfonsi, L., De Franceschi, G., Romano, V., Aquino, M. H. O., and Dodson, A.: Climatology of GPS ionospheric scintillations over high and mid-latitude European regions, Ann. Geophys., 27, 3429-3437, https://doi.org/10.5194/angeo-27-34292009, 2009.

Spogli, L., Alfonsi, L., Cilliers, P. J., Correia, E., De Franceschi, G., Mitchell, C. N., Romano, V., Kinrade, J., and Cabrera, M. A.: GPS scintillations and total electron content climatology in the southern low, middle and high latitude regions, Ann. Geophys.Italy, 56, R0220, https://doi.org/10.4401/ag-6240, 2013a.

Spogli, L., Alfonsi, L., Romano, V., De Franceschi, G., Francisco, G. M. J., Shimabukuro, M. H., and Aquino, M.: Assessing the GNSS scintillation climate over Brazil under increasing solar activity, J. Atmos. Sol.-Terr. Phy., 105, 199-206, 2013 b.

St-Louis, B. J., Trigg, D. F., and Coles, R. L.: INTERMAGNET Technical Reference Manual, Version 4.6, available at: www. intermagnet.org (June 2017), 2012.

Tanaka, T. and Hirao, K.: Effects of an electric field on the dynamical behavior of the ionospheres and its application to the storm time disturbances of the F-layer, J. Atmos. Terr. Phys., 35, 1443 1452, 1973.

Thomas, E. G., Baker, J. B. H., Ruohoniemi, J. M., Clausen, L. B. N., Coster, A. J., Foster, J. C., and Erickson, P. J.: Direct observations of the role of convection electric field in the formation of a polar tongue of ionization from storm enhanced density, J. Geophys. Res.-Space, 118, 1180-1189, https://doi.org/10.1002/jgra.50116, 2013.

Tsurutani, B., Mannucci, A., Iijima, B., Abdu, M. A., Sobral, J. H. A., Gonzalez, W., Guarnieri, F., Tsuda, T., Saito, A., Yumoto, K., Fejer, B., Fuller-Rowell, T. J., Kozyra, J., Foster, J. C., Coster, A., and Vasyliunas, V. M.: Global dayside ionospheric uplift and enhancement associated with interplanetary electric fields, J. Geophys. Res.-Space, 109, A08302, https://doi.org/10.1029/2003JA010342, 2004.

Tsurutani, B. T., Verkhoglyadova, O. P., Mannucci, A. J., Saito, A., Araki, T., Yumoto, K., Tsuda, T., Abdu, M. A., Sobral, J. H. A., Gonzalez, W. D., McCreadie, H., Lakhina, G. S., and Vasyliunas, V. M.: Prompt penetration electric fields (PPEFs) and their ionospheric effects during the great magnetic storm of 30-31 October 2003, J. Geophys. Res.-Space, 113, A05311, https://doi.org/10.1029/2007JA012879, 2008.

Van Dierendonck, A. J., Klobuchar, J., and Hua, Q.: Ionospheric scintillation monitoring using commercial single frequency C/A code receivers, In: ION GPS-93 Proceedings of the Sixth International Technical Meeting of the Satellite Division of the Institute of Navigation, 22-24 September 1993, Salt Lake City, USA, 1333-1342, 1993.

Yizengaw, E., Dyson, P. L., Essex, E. A., and Moldwin, M. B.: Ionosphere dynamics over the Southern Hemisphere during the 31 March 2001 severe magnetic storm using multiinstrument measurement data, Ann. Geophys., 23, 707-721, https://doi.org/10.5194/angeo-23-707-2005, 2005.

Zhang, Y. and Paxton, L. J.: An empirical Kp-dependent global auroral model based on TIMED/GUVI FUV data, J. Atmosph. Solar-Terrest. Phys., 70, 1231-1242, 2008. 